\title{
Target Price Accuracy in Equity Research
}

\author{
Stefano Bonini* \\ Bocconi University \\ Department of Finance \\ Via Roentgen 1, 20136, Milan, Italy \\ stefano.bonini@unibocconi.it \\ Laura Zanetti \\ Bocconi University \\ Department of Finance \\ Via Roentgen 1, 20136, Milan, Italy \\ laura.zanetti@unibocconi.it \\ Roberto Bianchini \\ REF Research Institute \\ Via Gioberti 520123 Milano - Italia \\ rbianchini@ref-online.it \\ Antonio Salvi \\ EM Lyon Business School \\ 23 Avenue de Collongue, 69134 Ecully cedex, France \\ salvi@em-lyon.com
}

This draft: $15^{\text {th }}$ March 2010

JEL classification Codes: $G 11, G 12, G 14$

Keywords: Target Prices, Analyst recommendation, security analysis.

We thank Ronald Bird, Michel Fleuriet, Vidan Goyal, Jay Ritter, Jan Yingua and seminar participants at the $30^{\text {th }}$ Journal of Banking and Finance Conference 2006, $4^{\text {th }}$ Portuguese Finance Network Conference 2006, EFMA Conference 2005, Asian Finance Association conference 2005, Bocconi University Finance Seminar 2005 for helpful comments and suggestions. We are indebted with Sergio Venturini at IMQ, SDA Bocconi and with Christian Brownlees at NYU Stern School of Business Volatility Insititute for support and help in data analysis. We thank Factset and Borsa Italiana for providing additional data. We are especially greateful to the editor (Martin Walker) and an anonymous referee. The authors acknowledge financial support from MIUR-Università Bocconi Ricerca di Base 2005. The ideas expressed in the paper do not necessarily reflect those of the authors' affiliation. Any errors remain our own.

* corresponding author: E-mail: stefano.bonini@unibocconi.it, Ph. +39 02 58363612; Fax +39 02 58363799 


\title{
Target Price Accuracy in Equity Research
}

\begin{abstract}
Analysts' target prices have received limited attention in academic research. In this paper we try to fill the gap by developing an innovative multi-layer accuracy metric that we test on a novel database. Our analysis shows that forecasting accuracy is very limited: prediction errors are consistent, auto-correlated, non-mean reverting and large (up to $36.6 \%$ ). The size of forecasting errors increases with the predicted growth in the stock price, the size of the company and for loss making firms. Additionally, the intensity of research and the market momentum negatively affect accuracy. These results suggest that analysts research is systematically biased which supports theoretical predictions by Ottaviani and Sorensen (2006). Since stock price forecasting is largely an unmonitored activity, market participants may fail in fully understanding this behavior thus not arbitraging away these inefficiencies.
\end{abstract}


Equity analysis provides investors with information on the current and future prospects of listed companies. While a great deal of academic research and business press attention has been devoted to the effect of analyst recommendation on stock returns or trading volumes, and to the accuracy of stock recommendations, the ability of target prices to predict future stock prices has, surprisingly, remained essentially unexplored. Yet, understanding analysts' target prices forecasting accuracy is relevant for three reasons. First, target prices are a straightforward measure of the potential change in value of the underlying security, which can be valuable to investors and may have an influence on their investment strategies. Therefore, understanding what is the relative quality of analysts in predicting future stock prices should be valuable information to investors. Secondly, the determinants of target prices are largely unexplored, which leaves room for providing investors additional hints on such price sensitive information that can be used to improve pricing efficiency and investment arbitrage. Thirdly, although some studies (Bradshaw and Brown (2006), Asquith et al. (2005)) have tried to investigate target price accuracy, we still lack a comprehensive performance valuation methodology

An additional motivation for this paper is given by the impressive and growing figures on global equity research spending. Figures reported in Johnson (2006) show that equity research by investment banks and independent firms has totaled over 20 billion USD in 2006. This amount of money ought to be considered an investment by research providers, since proceeds from the sale of the reports are modest. ${ }^{i}$ Yet, such an investment could be motivated by the potential support it offers to investors in making their portfolio allocation decisions. In efficient markets, such information should therefore yield robust estimations of future market prices, i.e. average target prices forecasting errors should distribute normally with zero average and known variance. Individual forecasting accuracy may pro-tempore deviate from a normal distribution but it should be randomly distributed with a zero average across the full-sample, as predicted by standard efficient markets theory. According to this hypothesis, research intensity - absolute and relative - should be positively related with accuracy, due to a learning effect, and, analogously, following Falkenstein (1996), prediction errors should 
be inversely related with some market factors like size and liquidity and positively with market momentum. On the other hand, accuracy should reduce for loss-making firms and firms with high $\mathrm{P} / \mathrm{B}$ ratios.

An alternative set of hypotheses of this paper is that analysts' target prices are consistently biased and that the size of the bias is increasing with the growth in value implied in each target price as suggested in Ritter (2006). Such an outcome would be a proof of an explicit action by research providers in introducing bias in markets, as suggested by theoretical predictions by Ottaviani and Sorensen (2006). The rationale for this behavior would be that, since no explicit control on the quality of target prices is enforced $^{\mathrm{ii}}$ by market participants, analysts may have an incentive to use this information strategically by delivering to the market over/under-optimistic information that less informed investors may incorporate in their investment strategies, resulting in a riskshifting effect. ${ }^{\text {iii }}$

A central issue of this research is to identify an appropriate measure of accuracy for target price forecasts. Barber et al. (2001) check whether analysts have superior forecasting ability by creating portfolios based on analyst qualitative recommendations and comparing them with an investment in the index. Similarly, Brown and Mohd (2003) try to measure analysts' accuracy focusing on future earnings forecasts. Both approaches share the characteristic of measuring relative performance at the end of a fixed period (12 months or the release of actual earnings by companies). Asquith et al. (2005) provide the first measure of target price accuracy introducing a simple metric which considers "accurate" a target if the underlying share price reaches or exceeds the target at the end of the time horizon. Unfortunately, when dealing with target prices this approach would lead to flawed results: a target price is generally assumed to be a prediction that is realized within a specified period, not necessarily at the end of that period. Bradshaw and Brown (2006) try to take this intuition into account by extending Asquith et al. (2005) and checking whether the price is met also at any time during the report time horizon. We believe though, that a quantitative accuracy metric is needed allowing also a control for the actual performance of the share price. We therefore introduce a comprehensive four-fold accuracy metric by which we jointly measure the 
accuracy of price forecast at the end of the forecasting period and at any moment in between. We then compare this measure with the actual returns realized by each stock.

In this paper we try to address these issues by looking at the Italian market which provides a unique research environment, for equity research disclosure is mandatory since 1999. Differently from any other dataset or market, we have the chance of studying a complete population with limited data snooping issues and with reduced selection bias: since analysts ex-ante know that the distribution of their reports will not be selective, they should provide additional effort in accurately forecast future prices.

Our results surprisingly do not support the null hypothesis showing that the frequency of accurate prediction is extremely low and the size of the prediction error is impressively large. Similarly, all tests run with a complete set of control variables fail to support the null hypothesis. Our findings are consistent with a recent paper by Bradshaw and Brown (2006) who addressed target price accuracy with a similar methodology in a different market.

The remainder of the paper is structured as follows: Section II reviews the literature; Section III describes data collection; Section IV introduces variables and research hypothesis; Section V presents results; Section VI concludes and introduces future research agenda.

\section{Related research}

Security analysts' research has received growing attention from both academics and regulators. Early studies have focused on market's reaction to analysts' earnings forecasts, recommendations and revisions. Almost uniformly, these analyses show nonzero, robust abnormal returns for earnings forecast revisions or new buy/sell recommendations. Abdel-Khalik and Ajinkya (1982) find significant abnormal returns around the publication week of revisions issued by Merrill Lynch analysts. Analogously, Lys and Sohn (1990) and Stickel (1990) document an information content associated with forecast revisions

The sign of abnormal returns was examined originally by Lloyd-Davies and Canes (1978). Additional evidence is provided by Bjerring et. (1983); Elton et al., 
(1986); Liu et al., (1990); Beneish, (1991); Stickel, (1995). Womack (1996) documents a significant initial price and volume reaction: size adjusted prices increase by $3 \%$ for buy recommendations and drop $4.7 \%$ for sell recommendations in the event window

Recent research investigates simultaneous changes in both earnings forecast and recommendation revisions. Francis and Soffer (1997) show that both factors fail to fully convey the information of the other signal. Their findings support the hypothesis that investors rely more heavily in their investment decisions, on repeated signals like revisions rather than on absolute forecasts. Stickel (1995) performs similar tests also controlling for the magnitude of the recommendation revision, the analyst's reputation, the size of the analyst's firm and the company's information. His results are consistent with those of Francis and Soffer while both show low statistical significance.

Target prices have been included in academic research only in recent studies. Brav and Lehavy (2003) show that target prices significantly affect market prices. The effect is unconditional on the simultaneous issuance of recommendations, similarly to Francis and Soffer (1997). The effects associated with a lack of independence are similar to those found in Michaely and Womack (1999), which documents that mean excess returns around a buy recommendation revision are lower when the recommendation is made by an underwriter rather than by an unaffiliated brokerage.

Bradshaw (2002) focuses on the joint publication of target prices and recommendations: on a sample of 103 reports, finding that the publication of a target price is positively correlated with more favorable recommendations. The paper closer in spirit to ours is Bradshaw and Brown (2006), who provide evidence of a differential ability by analysts in accurately predicting prices. Yet, as in Asquith et al. (2005), the authors look at the analysts' ability in predicting prices through a binary metric rather than developing a quantitative metric for interpreting the size and sign of forecast errors.

Asquith et al., (2005) examine the complete text of a large sample of analyst reports extracting information on earnings forecasts, recommendations and price targets. They show that additional information, such as the strength of the analyst's justifications, is also important and when considered simultaneously increases the significance of the information available in earnings forecasts, recommendation 
revisions and target prices. By controlling for the simultaneous release of other information, they conclude that analyst targets provide valuable analysis to the market.

Finally, Belcredi et al. (2003) and Cervellati and Della Bina (2004) show similar effects on the Italian market, yet only limitedly addressing target prices.

\section{Data collection}

\section{A. Regulatory issues}

We are motivated in the selection of a non-US sample of target prices by the uniqueness of Italy as the only country to require mandatory publication of any research issued by authorized financial intermediaries. Research activity is regulated by the Finance Code approved by the Italian Parliament in 1998. Section IV, ${ }^{\text {iv }}$ article 114 , states that "all non-public information which, if revealed to the market, may affect market prices of financial instruments, must be compulsorily transmitted to the public". It also established that CONSOB (Italian Stock Exchange Commission) must set and update rules concerning what is considered to be "price sensitive" information.

In 1999, CONSOB issued regulation \#11971. Article 69 states that research reports on listed companies must be sent to CONSOB and to the Italian Stock Exchange on the day they are issued for immediate publication in full format on the Stock Exchange website. Exception is given to research privately produced for financial institutions or specific customers which has to be transmitted to CONSOB and the Stock Exchange within 60 days of the issuing date. This delay is granted in order to preserve value for clients who pay for additional research. ${ }^{\mathrm{V}}$

This unique regulation provides a fertile testing ground for our research hypotheses for two reasons: first, we should not expect a sample bias due to discretionary disclosure of research activity by analysts. Second, price reaction to target price publication signals that this information is valuable to investors, therefore analysts' accuracy should be subject to continuous assessment by investors, who should penalize poor performer and, conversely assign a premium to consistent forecaster by, for instance, increasing their reputation or allowing them to secure more investment banking deals. In such an environment, since publication is mandatory, we then expect analysts to be on average accurate, with accuracy increasing over time. 
Differently from Italy, dissemination of US and European research is generally provided through agreements between research firms and private non-financial institutions such as Thomson Financial, Factset or Investars. By adopting privately distributed information the risk of incurring in a selection bias could be significant since participation to those data sources is not compulsory. To control for this potential sample bias we looked at data available from Factset JCF. This database is by-andlarge, the most detailed data source for European equity; yet, a query for the same sample period returns only 5466 reports, i.e. about $65 \%$ less than those recorded in our hand-collected population. ${ }^{\mathrm{vi}}$ Two additional differences are worth noting: first, the JCF database has no records for reports issued by important firms such as Goldman Sachs, Merrill Lynch or Julius Baer which, differently, are included in our database. Second, JCF collect reports from firms not included in our data like Morgan Stanley or West LB. The interpretation of these remarkable differences is two-fold: on one hand it supports the idea that since participation to data collection is a voluntary decision by research firms, publicly available sources may suffer a significant sample bias. ${ }^{\text {vii }}$ On the other hand, it suggests that mandatory disclosure as existing in the Italian market may be not welcome by research firms who may choose to avoid compliance by issuing from abroad. This intuition is supported by the fact that while our database is composed by an almost balanced number of foreign and domestic firms, the amount of research published is considerably skewed towards domestic analysts. This two-sided selfselection issue is potentially valuable to investors but since it requires extensive and separate analysis, we leave it for future research. ${ }^{\text {viii }}$

\section{B. Database construction}

We collect 17,397 research reports published from January $1^{\text {st }} 2000$ up to December $31^{\text {st }} 2006$ by 47 distinct research firms covering 98 companies listed on the Milan Stock Exchange and representing approximately 405.32 bn $€$ or $81,96 \%$ of the overall market capitalization. Assuming no regulation breach by research firms, this is the representation of the complete population of research published on companies listed in this market. We reduce the original sample to 16,100 reports keeping only reports satisfying two criteria: first each report accepted for inclusion in the database ought to 
represent companies continuously listed in the whole period of analysis. Therefore reports focusing on firms that went public later than January 1999 are excluded due to the potential of upward bias, as showed by Michaely and Womack (1999). Similarly, delisted companies are excluded since the research quality could have been biased by the delisting motivation with no chances for controlling this effect. Second, for each research firm, we exclude "single report companies", i.e. companies for which only one report has been published across the time interval of analysis. The above two criteria result also in excluding all reports targeting companies listed in the now extinct technological stock market ("Nuovo Mercato").

We further applied three additional filters: the first excludes all "damaged" reports and all "mirror" reports for a total of 2,273 reports or $13.07 \%$ of the original $\operatorname{set}^{\mathrm{ix}}$. The second filter generates an "informationally efficient" sample aimed at solving quasi-duplications: whenever two reports on the same company by the same research firm are available with a publishing date smaller or equal to 14 days, we exclude either the former or the latter according to the following principle: if the two reports present identical recommendations and target prices we exclude the latter (assuming a publishing error); if the two reports express different recommendations or target prices, we exclude the former (assuming that an unanticipated, extraordinary event occurred ${ }^{\mathrm{x}}$ ). This excludes 1,600 reports.

The third filter eliminates from the dataset reports on companies subject to equity changes within that report prediction horizon. We exclude reports on companies that realize buy-back or share split operations during the prediction period because such operations cause a jump in the stock price and an alteration of the portfolio return. This filtering excludes some further 194 reports.

Jointly, the three filters reduce the sample to 12,033 reports. Additionally, we further exclude 1,094 reports which do not disclose any target price. The final sample is thus given by 10,939 reports. Additional information about reported companies - such as market capitalization, daily closing prices, daily trading volumes has been collected by Datastream. Industry classification is based on FTSE Global Classification system "Economics group" level 3. Stock Market Index Composition was 
extracted from Datastream. Table 1 Panel A summarize the database construction process.

\section{TABLE 1 HERE}

\section{Descriptive Statistics}

Table 1, Panel A, B and C provides details of the sample.

The average coverage per company is 112 reports, but data on standard deviation and median hint at some skewness in distribution. The relative number of reports per company shows that the most-analysed company tops 414 reports, or just $3,78 \%$ on the total sample. Yet, the distribution of the number of reports across the companies is not completely uniform since 40 firms, representing just two quintiles of the sample, account for $79.06 \%$ of the total number of reports. Further inspecting the database constituents show that these firms are those with the highest market capitalization, which suggest, consistently with existing literature, that financial analysts focus more their attention on large stocks ${ }^{\mathrm{xi}}$.

Table 1, panel $\mathrm{C}$ shows summary statistics for reports distribution at the industry level. Data show that the financial industry is the most represented with 29 companies and 3,117 reports; Cyclical industries are also well represented both in terms of companies and reports. A measure of the thinness of the Italian Stock Exchange is given by figures on Non-cyclical services, Resources and Utilities which, with only two and three firms respectively, show the highest mean coverage of the sample.

Table 2 Panel A provides evidence on yearly and monthly reports distribution. Within each year, four accumulation points exist around the months of March, May, September and November which typically host major corporate events like shareholders' meetings, dividend distribution decisions or budget approval for future fiscal years. This pattern is consistent with the hypothesis that analysts update research with the arrival of new information.

TABLE 2 HERE 
Selected reports have been initially classified according to the original recommendation ranking adopted by each research firm to control the cross-sectional characteristics of our sample compared with other research. Since each firm adopts an individual scale, we re-classified recommendations on a standard five-point scale: "strong sell/sell/hold/buy/strong buy". The conversion criterion goes as follows: if the original scale is a five-steps scale with a central recommendation indicating a "standby" on the investment (such as 'neutral' or 'hold') we have converted the recommendation straightforwardly in our standard scale; if the original scale is a threesteps scale we have converted the central recommendation into a 'hold' and looked at both the recommendation and the target price for the upside and downside indications. We convert a buy with an implicit return above $20 \%$ into a strong buy and keep a buy for implicit returns below that level. Analogously we convert 'sell' recommendations into strong sells only when implicit loss is larger than $-20 \%$. Table Panel B provides summary statistics for the recommendation class distribution. Interestingly, there is not a significant reduction in the positive recommendation over time and similarly negative recommendation decrease.

Table 3 reports recommandations' transition matrix. The number of reports considered is less than that included in the full sample because we have excluded the last recommendation issued by each firm and reports published only once by a firm on a company.

\section{TABLE 3 HERE}

Most reports $(n=6287)$ reiterate the previous recommendation. Reiterations are represented in italics on the diagonal of the matrix in Table 3. 'Strong buy' and 'buy' reiterated recommendations account for $56.99 \%$ of total unchanged reports. Upgrade recommendations are defined as upward revisions of previous recommendations: they include all reports above the matrix diagonal. Similarly, downgrades are defined as downward revision of previous recommendations and include all reports below the matrix diagonal. 
Data show that upgrades and downgrades are most often towards the nearest recommendation class: buy to hold $(n=584)$, hold to buy $(n=695)$, strong buy to buy ( $n=401)$ and buy to strong buy $(n=448)$. The relative transition matrix indicates that across all recommendation classes, the most frequent update is a reiteration of the previous recommendation. When positive recommendations (strong buy/buy) change, they are often downgraded to the nearest-class recommendation (buy/hold) and, similarly, when negative recommendations change it is most often an upgrade to the nearest superior recommendation class.

The descriptive statistics provided in Table 3 are aligned with those reported in Asquith et al. (2005), Bradshaw and Brown (2006) and Brav and Lehavy (2002). This alignment suggests that, at the recommendation level, our sample doesn't show critical differences with those of other markets indicating that our results can be generalized.

\section{Accuracy metrics}

Our analysis addresses the accuracy of analyst target prices. ${ }^{\text {xii }}$ No previous studies have developed a comprehensive methodology for assessing forecasting accuracy. Asquith et al. (2005) test accuracy by a simple metric which considers "accurate" a target if the underlying share price reaches or exceeds the target at the end of the time horizon. In the same spirit, Bradshaw and Brown (2006) extend the analysis by checking whether the price is met also at any time during the report time horizon.

In this paper we aim at developing a multidimensional benchmarked metric for testing accuracy.

\section{Setting the Time Horizon}

Analysts generally do not make explicit assumptions on the time required by market prices to adjust towards the predicted target. Most of the time, when an explicit time is provided, it is equal to 12 months from the report's issue date. ${ }^{\text {xii }}$ A major concern is whether we should adjust time horizons for target price revisions. If a new report is issued before the end of the (implicit or explicit) time horizon, two options are available for defining time horizons: time horizons can be left unchanged, and accuracy measured on two partially overlapping periods; alternatively, time horizons can be reset by stopping the initial accuracy measure at the time of the update and generating a new 
measurement adopting the update's new time horizon (again, implicit or explicit). We believe that results calculated through flat, overlapping periods can be severely biased. In particular, we recognize three sources of measurement bias:

1. Joint existence of forecasts with opposite economic meaning;

2. Lack of factoring of analysts updating, in particular after significant jumps in stock market prices (market crashes/market bubbles);

3. Assumptions that investors adjust outstanding TP for corporate actions which have an impact on the nominal share price - such as splits and reverse stock splits;

\section{Opposite forecast.}

Analysts update existing target prices and recommendations by incorporating new information in outstanding estimates. This Bayesian process may generate the transition from one recommendation class to another. The transition is particularly meaningful when it suggests a shift in the sentiment on the stock (e.g. from positive to negative implicit return). Measuring forecast errors adopting a flat accuracy analysis period doesn't capture this information update as two outstanding reports with opposite signs in implicit return are treated as independent and equally meaningful advices which they clearly are not. This conflicting information is of questionable economic meaning but can be amended by dynamically adjusting the forecasting horizon dropping the oldest report issued by the same analyst on the same firm.

Jumps

When markets or single stocks experience significant jumps in prices, analysts and market participants react by adjusting their expectations and portfolio allocations. In these cases the value of analysts' forecasts stands in the timeliness of the revision and in its direction and magnitude as shown by Michaely and Womack (1999). Measuring accuracy with unadjusted forecast periods would fail to capture this effect as two target prices issued at different time would factor in different information sets.

Splits and reverse splits

When stock splits and reverse-stock splits occur, the nominal price of the share changes, carrying along the market price. Outstanding Target Prices therefore, should be 
adjusted to account for the corporate action. The adjustments are motivated by the evidence that different nominal prices have an impact on price volatility, as shown by Baker et al. (2009). Additionally, it is unlikely that investors would keep looking at Target Prices measured at different levels of nominal price.

These concerns can have severe impacts on the quality of the accuracy metrics. We therefore choose to adopt the following measurement rules, which are designed to overcome these concerns and represent an addition to the literature:

Measurement Rule 1: If target prices are issued with an explicit time horizon we check whether the market price reaches the target price at any moment between the issue date and the time-horizon final date, unless a new report is issued. In this case we consider the actual prediction date of the former report as the latter report issue date minus three days; ${ }^{\text {xiv }}$

Measurement Rule 2: if reports are issued without an explicit time horizon, we consider the time horizon to be the lesser between 12 months and the following report update minus three days.

A caveat applies with this approach: when analysts issue an updated forecast confirming the outstanding TP, the measurement rules require computing the accuracy of the first report, and start a new, independent estimation for the updated forecast. Thus, two forecasts with the same TP may be differently accurate. This outcome though is acceptable because forecasts are not time independent. In particular: updates always change the forecast horizon; additionally they are issued conditional on market conditions and underlying stock prices. As such, the same target price implies different implicit returns and carries a different meaning in a bull or bear market economic. Joint accuracy estimation through our multi-layer metric allows proper evaluation of these occurrences.

\section{Defining accuracy}


Ex-ante target prices convey an immediate performance prediction that we define "implicit return" which is given by the algebraic difference between the target price and the current market price.

Formally, we define implicit return (IR) as:

$$
I R=\left[T P_{t} / P_{t}\right]-1
$$

This prediction is met if at some point during or at the end of the time horizon, the underlying share price reaches the target price. Market prices, though, may not perfectly match the target; in this case the accuracy of a target price is given by the degree of proximity of the share price to the target. To capture accuracy at this level we develop two metrics, named "Ideal Strategy" (IS) variables, because it is dubious whether this level of accuracy can be valuable to investors, since understanding when a price is at its maximum level is almost impossible:

$$
\begin{gathered}
\delta_{1}=\left[P_{m} / P_{t}\right]-1 \\
\delta_{2}=\left(\left(T P_{t} / P_{m}\right)-1\left|T P_{t}>P_{t} ; 1-\left(T P_{t} / P_{m}\right)\right| T P_{t}<P_{t} ;\right)
\end{gathered}
$$

where:

$t$ : report issue date by firm $i$ on company $j$

$P_{t}$ : stock market price at the research report publication date $t$

$T P_{t}$ : target price given by analyst at the research report publication date $t$

$P_{m}:$ maximum/minimum price level within the prediction time horizon.

Recommendation can be divided into two groups inferring the expected outcome: positive or neutral performance (Strong buy/buy and hold recommendations) and negative performance (sell and strong sell). Accordingly, when calculating all $\delta$ variables implicit returns, we use the maximum price if, at $t, T P_{t}>P_{t}$. Alternatively, we use the minimum price if, at $t, T P_{t}<P_{t}$.

$\boldsymbol{\delta}_{1}$ is defined as the "ideal" return control variable calculated as the difference between the maximum/minimum price over the time horizon and the issue date share price. A different way to interpret $\delta_{1}$ is the maximum potential return an investor could 
earn if (s)he could perfectly foresee future prices along the investment time-horizon and identify a maximum/minimum.

$\boldsymbol{\delta}_{2}$ measures the $I S$ prediction error for any report as the difference between the issued target price at $t$ and the maximum/(minimum) market price in the relevant prediction time-horizon. This variable expresses ex-post analyst prediction error compared to stock market price. To compute prediction errors we look at target prices at the report issue date for each report: when at $t$ the target price is larger than the current market price we interpreted a positive difference between $T P_{t}$ and $P_{m}$ as "upside overshooting", i.e., a prediction of greater increase in the maximum market price than eventually realized by each share. Conversely, a negative difference is considered to be a "conservative" prediction. Analogously, when at $t$ the target price is smaller than the market price, a negative difference between $T P_{t}$ and $P_{m}$ means that the analyst has predicted greater downside than the real price downside observed ex-post on the stock market. We name this phenomenon as "downside overshooting" and the opposite sign phenomenon as "conservative".

Assuming that investors cannot effectively predict when a maximum/minimum price is achieved on the market, we model two alternative "Feasible Strategy" (FS) variables:

$$
\begin{gathered}
\delta_{3}=\left[P_{t+n-3} / P_{t}\right]-1 \\
\delta_{4}=\left(\left(T P_{t} / P_{t+n-3}\right)-1\left|T P_{t}>P_{t} ; 1-\left(T P_{t} / P_{t+n-3}\right)\right| T P_{t}<P_{t} ;\right)
\end{gathered}
$$

where:

$t+n$-3: date (minus three days) of the subsequent report issued by firm $i$ on company $j$ or the end of the prediction time horizon

$P_{t+n-3}:$ stock market price at $\mathrm{t}+\mathrm{n}-3$

$\boldsymbol{\delta}_{\mathbf{3}}$ is the second control variable measuring the "feasible" return as the difference between the price at the end of the time horizon and the report's issue date share 
price. Analogously with $\delta_{1}$ we can interpret it as the return yielded to investors by a buy-and-hold strategy in the share over the whole time horizon.

$\boldsymbol{\delta}_{4}$ measures the $F S$ prediction error for any report as the difference between the issued target price and the stock market price at the end of the investment time-horizon. Prediction error interpretation goes the same way as for $\delta_{2}$ : when the target price is higher than the market price at $t$ we interpreted a positive difference between $T P_{t}$ and $P_{t+n-3}$ as "upside overshooting", i.e., a prediction of greater increase in market price than eventually realized by each share at the end of the time horizon. Conversely, when the target price is smaller than the market price at $t$, a negative difference between $T P_{t}$ and $P_{m}$ is defined as "downside overshooting".

Figure 1 gives a graphical representation of the four variables. ${ }^{\mathrm{xv}}$

\section{INSERT FIGURE 1 HERE}

Figure 2 shows variables' sign interpretation: if TP is greater than market price at $t$ (top side of the graph), a positive sign for variables $\delta_{2}$ and/or $\delta_{4}$ means that the issued TP has proved to be greater than the realized market price at the end of the relevant time horizon i.e. an "overshot" forecast. A negative sign means that the realized market price has exceeded the issued TP i.e. a "conservative" prediction. For the bottom part of the graph (when TP is lower than current market price at $t$ ), overshooting occurs when we obtain a positive sign, i.e., when the issued TP is lower than the realized market price.

\section{INSERT FIGURE 2 HERE}

In this paper we model a null hypothesis of zero average forecast error as follows.

Let's assume $j$-th stock price follows a standard random walk process with drift $\mu_{j}$. The price of any stock $j$ at time $t$ will then be given by:

$$
P_{t, j}=\mu_{j}+P_{t-1, j}+\varepsilon_{t, j} \quad, \quad \varepsilon_{t, j} \sim \mathrm{N}\left(0, \sigma^{2}\right)
$$


Different expectations on prices are incorporated in the expected drift, therefore, the ex-ante expected market price for each stock can be written as:

$$
E\left(P_{t, j}\right)=E\left(\mu_{j}\right)+P_{t-1, j}+\varepsilon_{t, j}, \quad \varepsilon_{t, j} \sim \mathrm{N}\left(0, \sigma^{2}\right)
$$

Under these conditions, it must also be that expected prices are given by the cross-section of expected drifts by all market participants. This implies that, if markets are sufficiently efficient, expectations converge to the realized value, i.e. $\sum_{i=1}^{n} E\left(\mu_{j, i}\right) \omega_{i} \rightarrow \mu_{j}$, where $\omega_{i}$ is an appropriate weighting factor and $n$ is the investor population. Since prices are given by past-prices - which are common knowledge - and expected drifts, this implies that $E\left(P_{t, j}\right) \rightarrow P_{t, j}$ for every stock, given that efficiency requires errors to be normally independently, identically distributed with zero mean and known variance. Target prices, though, can be interpreted just as the expectation on future stock prices by each individual analyst $i$. i.e. $T P_{t, j, i}=E\left(P_{t, j, i}\right)$. Since analysts are skilled, informed investors constituting a large and meaningful proxy of the investor population, we conjecture that their cross-sectional average forecast should be a good estimator of future prices, i.e. that their prediction errors, measured as $T P_{t, j, i}-P_{t, i,}$, should be normally distributed with zero mean and known variance. The $\delta_{2}$ and $\delta_{4}$ metrics can thus be considered as proxies for $T P_{t, j, i}-P_{t, j}$. This condition offers a desirable testable property which is that prices should not be auto-correlated over any interval. Therefore, failure in finding zero autocorrelation would be a strong hint at the existence of systematic additional drifts in analysts' predictions i.e. a bias. In fact, temporary nonzero prediction errors due to unexpected jumps in drift could well be observed but these should be random and deviations from zero in prediction errors across different periods should be non-correlated.

\section{How accurate are analysts?}

Brav and Lehavy (2003) showed that the informativeness of qualitative recommendation is different among recommendation class. Intuitively, qualitative recommendations and Target Prices should provide homogeneous information to investors, i.e. a Strong Buy should be associated with a high implicit return Target Price (adjusted for the market momentum). In table 4 we follow this intuition adopting 
recommendation classes as proxies of different levels of implicit returns trying to explore the existence of differential predictive ability. Fore each recommendation class, in column 1 we report predicted implicit returns computed as the difference between target price and the market price at the issue date. In Column 2 we report the quantitative change in Target Price revisions measured as the percentage difference between a target price and its closest revision. Column 3 and 4 report values for the metrics used in Bradshaw and Brown (2006) to allow comparison across the two samples. Columns 5 and 6 report figures for the 'Ideal Strategy' (IS) accuracy control metric and variable respectively. Columns 7 and 8 report figures for the 'Feasible Strategy’ (FS) accuracy control metric and variable respectively.

\section{TABLE 4 HERE}

Figures indicate that implicit returns are decreasing in recommendation classes, ranging between $36.93 \%$ for 'strong buy' recommendations to $-31.99 \%$ for "strong sell" recommendations. This result is consistent with a rational approach to forecasting: stocks that are less favorably recommended by qualitative measures are also expected to grow less. Intuitively, both implicit expected returns and TP changes should decrease the more unfavorable is the revision. Indeed, that is confirmed by our data which also show that negative recommendations are associated with larger and more skewed target price revisions. Columns 3 and 4 report results for the binary metrics adopted in Bradshaw and Brown (2006). TPmetANY is a percentage value indicating the number of target prices for which the market price at any time during the forecast horizon reaches or exceeds the prediction. Similarly, TPmetEND captures the number of forecast matched or exceeded by the stock price at the end of the forecast window. Our figures are $33.12 \%$ and $20.0 \%$ as opposed to Bradshaw and Brown (2006) figures of $45 \%$ and $34 \%$. This difference is the first notable effect of the different accuracy metric specification we propose in this paper.

Columns 5 and 6 report figures for the $I S$ control metric and variable respectively. Overshooting ${ }^{\mathrm{xvi}}$ is statistically significant and large, with absolute values 
of $22.26 \%$ and $19.75 \%$ respectively for "strong buy" and "strong sell" classes, which, interestingly, show similar overshooting. The "buy" class shows a similarly positive overshooting of $6.98 \%$ while sell and hold classes are more accurate with generally conservative estimates. This last result can be better interpreted looking jointly at the control metric $\delta_{1}$ and the implicit return: target prices in this category are generally close to the market price at the issuance date indicating the absence of a clear expectation of price change, as supported by the large volatility of both the realized returns and the prediction errors. This behavior is more evident for the "sell"class.

$I S$ metrics assume that investments in stocks are undertaken at the report issue date and liquidated once the price reaches its maximum(minimum) level within the investment time-horizon. Most of the time, though, as shown by columns 5 and 6 , prices never get reasonably close to the expected target price level, ${ }^{\text {xvii }}$ calling into question the hypothesis that, on average, investors can discriminate between market prices and understand which price represents a "real" maximum. In fact, less informed investors in high implicit return stocks, when observing large deals of expected growth not yet reflected by market prices, may be likely to wait for the price to further increase.

A more realistic investment strategy is developed through the $F S$ variables which assume an investor to open the position on any report issue date closing it at the end of the time horizon. ${ }^{\text {xviii }}$

$F S$ data are reported in columns 7 and 8 and surprisingly, this strategy yields very small and limitedly differentiated returns for the Hold, Buy and Strong Buy recommendation classes. Overshooting is significantly larger with the same signs of $I S$ variables. The highest overshooting is for the 'Strong Buy' class with 36.85\%. These results indicate a smaller accuracy than those in Asquith et al. (2005) but are aligned with those in Bradshaw and Brown (2007) and suggest that when reports are issued there is a significant effect on market prices which allow positive $I S$ returns expressed by variable $\delta_{l}{ }^{\text {xix }}$ Eventually though market prices reverse yielding a negative return on a buy-and-hold strategy position opened at the report issue date and closed either at the first update or after 12 months, whichever comes first. Yearly results reported in Appendix A, confirm the aggregate evidence. Interestingly, accuracy seem to fluctuate over time with large forecast errors diminishing over time and then resuming in the last 
year. Following Barber et al. (2006) we can interpret this pattern as a lagged response by analysts to changing market conditions: analysts fail to capture market reversals and start adjusting forecasts too late, thus generating larger prediction errors.

These striking initial results, call for testing the randomness in the observed biases. As previously shown, a zero forecasting error null hypothesis implies that deviations from zero - possibly given by unanticipated changes in drift - should be observed with zero autocorrelation across time for any lag and in non-stationary errors. We test these properties ${ }^{\mathrm{xx}}$ by running the following $n$-lagged $A R(n)$ Autoregression model for each analyst and for the whole sample:

$$
\mathrm{Y}_{\mathrm{i}, \mathrm{t}}=\alpha_{i}+\beta_{\mathrm{i}} \mathrm{Y}_{\mathrm{i}, \mathrm{t}-\mathrm{n}}+\varepsilon_{\mathrm{i}}
$$

where:

$i$ : the $\mathrm{i}$-th firm for which the test is run

$t$ : the time operator

$n$ : number of lags

$\alpha$ : the model estimated parameter for the mean component

$\beta$ : is the autoregressive component for the n-lag

In such a model, the null hypothesis of zero and non autocorrelated forecast error would be captured by a zero (or not significant) value for the intercept $\alpha$ and a non significant autoregressive parameter. We have run the AR model with independent variable specifications up to three lags. Further lags do not meaningfully add to the model explanatory power. Results reported in Table 5 unexpectedly reject the null hypothesis: in the full sample analysis for both the $\delta_{2}$ and $\delta_{4}$ variables the intercept and the parameter for the AR component are positive and significant at the $1 \%$ level indicating that analyst systematically overshoot forecast, that this bias is persistent over time and is not mean-reverting. Looking at individual firms estimates, we find a similar pattern for both the estimated mean error parameter and the $A R(n)$ component. Intercepts are negative in only 3 out of 19 significant intercepts for the $\delta_{2}$ variable and never negative and significant for the $\delta_{4}$ variable. The autoregressive component is always positive with only one weak exception at the $10 \%$ level. An implication of this 
result is that forecast adjustment will be "sticky" which supports the previously discussed evidence of analysts lagged response to market reversals.

These results robustly show the existence of a systematic bias in analysts' forecasts. However, little can be inferred on the determinants of these biases.

\section{What determines forecasts accuracy?}

The preliminary results obtained so far cast doubts on the research industry quality. Yet, some factors may play a different role in determining analysts' accuracy, yielding differential forecasting qualities. In this section we try to explore the determinants of forecasting accuracy.

\section{A. Research intensity}

Analysts perform equity research according to a rather stringent focus on one specific industry, country or both. By repeatedly addressing the same topic, they gain exposure to the value drivers, build experience and, more generally, should show increasing efficiency in their task. It is then reasonable to expect such a learning curve effect to be reflected by forecasting accuracy being increasing in the amount of research published. We check this hypothesis by testing the relation between research intensity, measured as natural logarithm of the number of reports published annually by each research firm $i$ on all companies and the magnitude, and the sign and size of prediction errors for the yearly averages of the $\delta_{2}$ and $\delta_{4}$ measures. We model our test in the following functional form:

$$
\begin{aligned}
& \bar{\delta}_{2, i}=\alpha+\beta N^{\circ} \text { report }_{i}+\varepsilon_{i} \\
& \bar{\delta}_{4, i}=\alpha+\beta N^{\circ} \text { report }_{i}+\varepsilon_{i}
\end{aligned}
$$

where $\bar{\delta}_{2, i}$ and $\bar{\delta}_{4, i}$ are the yearly averages of prediction errors $\delta_{2}$ and $\delta_{4}$ for each firm $i$.

\section{TABLE 6 HERE}


Regressions results are reported in Table 6. IS results $\left(\delta_{2}\right)$ are significant and do not confirm the learning effect indicating a positive relationship between research intensity and prediction errors. In particular, publishing more than 10, 50 and 100 reports increases errors by $3.48 \%, 6.06 \%$ and $7.04 \%$ respectively. This result is surprisingly large given that many research firms issue over 200 reports annually. Results for the $F S$ metric $\left(\delta_{4}\right)$ are negative as expected but statistically insignificant. Furthermore, the large and significant intercept confirm preliminary results reported in Table 4 which indicate that errors measured at the end of the forecasting horizon are consistently larger than at any point within the prediction window.

Interpreting this result is not straightforward but a potential explanation can be that when a firm publishes a report it is revealing some potentially valuable private information. Since markets react significantly at the arrival of new information and little control on this part of the research activity is exerted, then firms may have an incentive in overshooting predictions in order to maximize the price effect associated with the publication of research. If such a behavior exists and is reflected in inaccuracy increasing in the volume of reports published, we should also expect to observe dispersion of ex-ante implicit returns to be increasing in the amount of research published. The following test aims at cross-checking the previous results by regressing implicit returns volatility - measured as standard deviation of the $T P_{t, i} / P_{t}$ variable - on research intensity, calculated as the absolute amount of reports published by each bank.

$$
Y_{i}=\alpha+\beta N^{\circ} \text { report }_{i}+\varepsilon_{i}
$$

where $Y_{i}=$ standard deviation of $\left(\left(T P_{t, i} / P_{t}\right)-1\right)$ for firm $i$.

Regression results are reported in column three of Table 6. The volatility estimated parameter is positive and significant indicating that the higher the research effort and the larger the dispersion of implicit returns, i.e. predictions. A rival interpretation of this result could be that providing forecasts on a larger number of different companies implies a greater dispersion of predictions given that shares are endogenously differently priced. Yet, this effect should be more than compensated by 
lower dispersion due to greater clustering as increasing the research output generally also results in more reports on each company by the same research firm.

The evidence shows that when research is scarce, analyses are more conservative while conversely, an increasing number of reports is associated with larger prediction errors and greater dispersion of forecasts. These results could suggest that analyst may use research to influence market prices: the scattered publication of a few reports has, in fact, less chances of influencing market price. On the other hand, continuous coverage and reiteration of extreme valuations can build more confidence on one firm's ability thus driving investor behavior.

A caveat in previous results is given by a potential variable misspecification: adopting as the independent variable the 'overall coverage' measure (i.e. total reports published by one form over total amount of report published) may lead to biased results. In fact, a standard learning curve argument would suggest that a deeper coverage of one specific company should be negatively correlated with the size of prediction errors: the greater the knowledge of a company's activity the better the ability to correctly estimate value. With respect to our analysis, this could yield to a double-signed relationship: positive correlation between errors and absolute coverage by each firm (due to a "skills dispersion" effect) and negative correlation between prediction errors and relative coverage by each firm (due to a "knowledge effect"). Yet, running control regressions with differently specified variables doesn't provide evidence of differential results but significantly reduces results' significance.

\section{B. Recommendation classes and revisions}

As introduced in Section VI we try now to understand the simultaneous joint effect on accuracy generated by recommendations and the point measure of expected return (or loss) expressed by the Target Price. The test regression takes the following form:

$$
\begin{aligned}
& \delta_{2, j, i}=\alpha+\beta_{1}\left(\left(T P_{t, j, i} / P_{t, j}\right)-1\right)+\beta_{2} \text { Strong buy }+\beta_{3} \text { Buy }+\beta_{4} \text { Sell }+\beta_{5} \text { Strong sell }+\varepsilon \\
& \delta_{4, j, i}=\alpha+\beta_{1}\left(\left(T P_{t, j, i} / P_{t, j}\right)-1\right)+\beta_{2} \text { Strong buy }+\beta_{3} \text { Buy }+\beta_{4} \text { Sell }+\beta_{5} \text { Strong sell }+\varepsilon
\end{aligned}
$$


where $\delta_{2, j, i}$ and $\delta_{4, j, i}$ are the prediction errors for each firm $i$ on company $j,\left(T P_{t, j, i} / P_{t, j}-1\right)$ represents the implicit return expressed by target price at the time of report publication and the recommendation variables (StrongBuy; Buy; Sell; StrongSell) are dummies taking a value of 1 if the Target Price is associated with a specific recommendation and 0 otherwise.

\section{TABLE 7 HERE}

Overall significance for regressions is high $(\mathrm{F}=2,429.06$ and 646.1 , one-tailed $\mathrm{p}<0.01)$ with an adjusted $R^{2}$ for the $\delta_{2}$ regression of $52.6 \%$ and $22.8 \%$ for the $\delta_{4}$ regression. Results show that the largest effect on accuracy is given by the implicit return associated with each target price $(0.789 \mathrm{t}=99.37$, and $0.612, \mathrm{t}=48.04$, one-tailed $\mathrm{p}<0.01$ for the $\delta_{2}$ and $\delta_{4}$ respectively): the greater is the predicted return, the smaller is accuracy. Since we measure prediction errors, a positive sign indicates overshooting by the analyst. Furthermore, the more extreme is the recommendation class and the larger is the effect on accuracy. These results are consistent with Bradshaw and Brown (2006) which also documented a large and negative effect of target price implicit returns on analysts' accuracy.

Francis and Soffer (1997) and Brav and Lehavy (2003) documented that recommendation revisions have a non negligible effect on market abnormal returns. If the market reacts to revisions, we should also expect target prices accuracy to be affected by the evolution of judgment by analysts. To test target price sensitivity to recommendation revisions, we regress prediction errors on two dummy variables indicating whether a recommendation is an upgrade or a downgrade of previous research on the same company by the same firm, controlling for target prices implicit returns. The 'reiteration' class is excluded and captured by the intercept. The regression takes the following form

$$
\begin{aligned}
& \delta_{2, j, i}=\alpha+\beta_{1}\left(\left(T P_{t, j, i} / P_{t, j}\right)-1\right)+\beta_{2} \text { Upgrade }+\beta_{3} \text { Downgrade }+\varepsilon \\
& \delta_{4, j, i}=\alpha+\beta_{1}\left(\left(T P_{t, j, i} / P_{t, j}\right)-1\right)+\beta_{2} \text { Upgrade }+\beta_{3} \text { Downgrade }+\varepsilon
\end{aligned}
$$


where $\delta_{2, j, i}$ and $\delta_{4, j, i}$ are the prediction errors for each firm $i$ on company $j,\left(T P_{t, j, i} / P_{t, j}-1\right)$ represents the implicit return expressed by target price at the time of report publication, Upgrade, Downgrade are dummy variables indicating whether the recommendations was an upgrade or a downgrade on the report previously outstanding.

Regressions are strongly significant with adjusted $R^{2}$ of $53.9 \%$ and $23.1 \%$ for the $\delta_{2}$ and $\delta_{4}$ variables respectively. The implicit return coefficient is positive and highly significant indicating that a large part of every target price forecast is systematically not met. This result holds for both variables with similar significance. More interestingly, we document that recommendation revisions (on both sides, i.e. up and down) have a small positive impact on accuracy. We interpret this result as an indication of systematic overshooting by analysts: since an overwhelming majority of reports largely overshoots target prices and most revisions are to the nearest recommendation class, a recommendation upgrade or downgrade should strengthen the analyst indication expressed by the target price, ideally delivering a valuable additional information to investors. Yet, regression coefficients are small and non-significant except for downgrades on the second accuracy variable, thus limiting the absolute value of this additional piece of information.

\section{TABLE 8 HERE}

\section{Market factors}

Investors are generally more attracted by large, high growth, highly liquid stocks. ${ }^{\text {xxi }}$ Forecasting accuracy should therefore increase with these factors. Conversely, accuracy should be lower whenever fundamental factors are more uncertain as for lossmaking and high $\mathrm{P} / \mathrm{B}$ ratio firms. To control whether this attention is reflected in a different degree of predictive power by analyst recommendation we run the following regressions:

$$
\begin{gathered}
\delta_{2, j, i}=\alpha+\beta_{1}\left(\left(T P_{t, j, i} / P_{t, j}\right)-1\right)+\beta_{2} M V+\beta_{3} C O V R A T I O+\beta_{4} M O M E N T U M+\beta_{5} E P S+ \\
+\beta_{6} P / B R A T I O+\beta_{7} M K T . R E T+\varepsilon
\end{gathered}
$$




$$
\begin{gathered}
\delta_{4, j, i}=\alpha+\beta_{1}\left(\left(T P_{t, j, i} / P_{t, j}\right)-1\right)+\beta_{2} M V+\beta_{3} C O V R \text { RATIO }+\beta_{4} M O M E N T U M+\beta_{5} E P S+ \\
+\beta_{6} P / B \text { RATIO }+\beta_{7} \overline{M K T} \cdot R E T+\varepsilon
\end{gathered}
$$

where:

$\left(\left(T P_{t, j, i} / P_{t, j}\right)-1\right)$ : percentage implicit return at target price issuing. Prediction errors should be independent from the stocks expected change in price, therefore we expect this variable to be not significant in sign.

MV: company market value. The expected sign for this variable is negative, since the larger the company, the more it should be traded and therefore the more accurate should analysts predictions be

COV_RATIO: number of reports issued by analyst $i$ divided by total reports considered. The predicted sign is negative due to a "learning effect".

MOMENTUM: market momentum variable given by the raw returns of the market index in the six months before the report's issuance date. This variable is a proxy for the relative growth level of the market. We expect a negative sign because of the inverse relationship between the change in stock prices and the magnitude of the prediction errors on a target prices.

EPS: a dummy variable equal to 1 if the company EPS consensus is positive and zero otherwise.

P/B RATIO: a variable equal to the current level of the $\mathrm{P} / \mathrm{B}$ ratio at the report issuance date.

MKTRET: is the the market return calculating for each TP's forecasting period

Column 1 in Table 9 reports results for $\delta_{2}$.

\section{TABLE 9 HERE}

The implicit return variable is large, positive and strongly significant suggesting that the higher the predicted growth in price, the larger the average forecast error. This result is somehow surprising because the error sign has an ordinal value: positive errors indicate overstated predicitions (overshooting) and vice-versa, which further shows that 
errors are one-sided in contradiction with the randomness in forecast errors assumption which is required for supporting the null hypothesis of unbiased predictions. This evidence is further supported by the results for the coverage ratio (COV_RATIO) variable which are aligned with our previous results and indicate that analysts are increasingly inaccurate in the amount of research published. Interpretations of this result could be related with a "herding" behavior as documented by Welch (2000), who provide evidence of analysts publication dates clustering and estimates converging the larger the volume of research published. Not surprisingly, the market momentum (MOMENTUM) parameter indicates that analysts are influenced by previous market conditions and tend to overstate predictions in upward markets. The EPS dummy variable provides full support to the intuition that loss-making firms challenge more intensively analysts' skills: the negative and significant parameter suggests that errors reduce on average by $.5 \%$ if companies have positive consensus EPS at the target price issuance date. Finally, the $\mathrm{P} / \mathrm{B}$ ratio does not provide support to the hypothesis that accuracy should be on average smaller for high $\mathrm{P} / \mathrm{B}$ ratio companies due to the higher intangible value component. Although very small, the negative sign implies that analysts can better capture the price drivers for these stocks than for more traditional companies.

Results reported in Table 9 column two, for the $\delta_{4}$ variable, offer interesting intuitions. First, prediction errors are larger in the implicit return, which is not surprising given the greater magnitude of the $\delta_{4}$ measure as opposed to the $\delta_{2}$ highlighted in table 4 . Second, the sign of the coverage ratio is negative and opposite to that estimated in the $\delta_{2}$ analysis. We interpret this result as follows: when the coverage increases, analysts make better predictions for long term movements than short term ones. Higher target prices therefore, translate in higher short term errors as measured by the $\delta_{2}$ variable but relatively smaller errors over the full prediction horizon. Similarly, the opposite sign of the momentum regressor suggests that analysts tend to overestimate the price effect of an upward market trend which eventually translates in growing prices but at a smaller pace than predicted. This implies that target prices are set at comparatively higher levels than in downturn trends resulting in higher $\delta_{2}$ and relatively 
smaller $\delta_{4}$ errors. It is worth noting though, that this doesn't affect the absolute magnitude of errors which is consistently larger in the $\delta_{4}$ case.

Third, the EPS parameter is consistent in sign with that estimated in the $\delta_{4}$ regression and larger in magnitude, offering additional support to the hypothesis that, when companies have negative profits, analysts' accuracy decreases significantly.

Finally, the $\mathrm{P} / \mathrm{B}$ ratio sign is positive and significant as originally expected but in contrast with our previous result. The explanation for this apparent contradiction is twofold: first, the higher the $\mathrm{P} / \mathrm{B}$, the higher the chances that the stock-price is either overvalued or close to its highest price. This in turn implies that prices are likely to fall below this value in the long run, in line with a mean-reverting process raising the magnitude of the $\delta_{4}$ error. Second, high $\mathrm{P} / \mathrm{B}$ ratios suggest that companies have a large component of intangible value and a potential risk of overvaluation. It should therefore be the case that when $\mathrm{P} / \mathrm{B}$ ratios are very high, the price-change expectation is likely to become negative. In such a case we should observe a different signal conveyed by this explanatory variable conditional on forecasts being negative or positive. The analysis in Subsection D addresses this issue

To confirm the absence of any misspecification in the tests, we have controlled regression residuals through graphical analysis without finding any evidence of nonnormality of the errors, which allow us to validate the model.

\section{Recommendation class breakdown}

In Table 4, we have found convincing evidence that prediction errors are not uniformly distributed across recommendation classes and implicit return classes. To test this implication we have run multivariate regressions on two different sample groupings. We first group recommendations into three classes: (Strong buy/buy), (Hold), (Sell, Strong Sell) to understand whether positive, neutral or negative expectations have any differential effect on prediction errors. We then construct a second sub-sample based on the realized signs of analysts' prediction errors, i.e. $\delta_{\mathrm{i}}>0$ and $\delta_{\mathrm{i}}<0$. Since a positive sign in prediction errors represents overshooting while a negative sign indicates conservative estimates, we may expect more significant results from a narrower analysis. More specifically, we expect regressions to be more 
significant for more favorable recommendation classes and for positive estimation errors.

Results presented in Table 10 confirm our hypotheses: at both levels of breakdown, reports' prediction errors are larger for favorable recommendation classes and are strongly, positively correlated with the sign of the prediction errors.

\section{TABLE 10 HERE}

Inspecting the 'StrongBuy-Buy' class we observe that significance results are aligned with those of the general regression presented in Table 9 which is consistent with the distribution of reports across classes presented in Table 2 Panel B.

These tests allow a better explanation of the evidence on the opposite signs of the $\mathrm{P} / \mathrm{B}$ ratio obtained in Table 9 . Results clearly show that the $\mathrm{P} / \mathrm{B}$ ratio sign is negative and significant for negative predictions (Sell and Strong Sell) which suggests that when $\mathrm{P} / \mathrm{B}$ are very high, analysts tend to correctly capture the overvaluation risk and accordingly issue negative recommendations (and target prices). On the other hand, for positive recommendations (Buy and Strong buy), analysts seem to signal the market that the current level of the $\mathrm{P} / \mathrm{B}$ ratio to the market, and by construction of the current market price, has not reached its maximum level allowing room for further stock price growth. Yet, the extent of this growth is easily overestimated resulting in increased prediction errors.

Similar inferences can be drawn for the evidence on EPS signs: for negative recommendation and conservative price estimates, the sign of the EPS explanatory variable is positive suggesting that it's simpler to predict downward price adjustments for loss making companies. Yet, this apparent performance is mitigated by observing that prices are already low and since stock prices are obviously inferiorly bounded, predictions cannot be overshot too much.

\section{Conclusions and future research agenda}


Using a large and uniquely developed database of analyst recommendations issued on companies listed on the Italian Stock Exchange, we examined the effectiveness of target prices published in research reports to anticipate future market prices efficiently. We expected target prices to be accurate measures of future stock market prices as implied by efficient markets hypotheses, implying that prediction errors should distribute with zero average and known variance, departing only randomly from expected values. Additionally, our hypotheses assumed that analysts' accuracy should be increasing in the amount of research performed according to a learning curve effect. Other market factors like size, liquidity should also increase accuracy because analysts should compete more aggressively, through superior quality, on the most represented stocks in investors' portfolios.

Surprisingly our hypotheses are not supported by empirical results: prediction errors are consistently different from zero, auto-correlated, non-mean reverting and positive in signs, which suggest the existence of a systematic upward bias. This intuition is further confirmed by looking at single recommendation classes and controlling for the level of the ex-ante implicit return. To better understand these results we run a set of tests aimed at identifying the determinants of target price accuracy. Consistently with previous results we had to reject our hypotheses. We found analysts accuracy to be negatively correlated with research intensity contradicting the conventional learning curve intuition. We also find strong evidence that fundamental factors like the level of the EPS consensus and the P/B ratio help in explaining analysts' accuracy. In particular, the former indicate that when companies are loss-making accuracy drops if analysts are predicting a growth in the stock price. Differently if analysts are forecasting downard price changes for loss-making firms, accuracy increases. Similar arguments have been observed for the $\mathrm{P} / \mathrm{B}$ ratio: analysts are slow in recognizing when a stock is approaching exceedingly high levels and show a consistent overoptimism. Differently, when the P/B level justifies a negative outlook, analysts seem to better capture the future price movements.

These results suggest that analysts may have not an incentive in truthfully revealing their information, introducing a bias in target price forecasting as predicted by Ottaviani and Sorensen (2006): since target price issues have a positive and significant 
price effect as first documented by Liu et al. (1990), issuing overstated predictions may affect more heavily stock prices; firms then could anticipate this phenomenon by opening and/or closing investment positions accordingly, thus transferring risks from more informed investors to less informed investors. Since target price forecasting is byand-large an unmonitored activity, market participants may fail in fully understanding this behavior thus not arbitraging away these inefficiencies.

Our research leaves some questions unanswered: first, can we find additional evidence on the source of the biases? Looking at institutional investors' ownership in publicly traded stocks should shed some light on whether investment firms portfolio management is correlated with research publication. Second, since target price forecasting has a large effect on prices, why did not the market react so far? Third, we observed that some companies do not participate in voluntary data collection by data provider such as Factset or Thomson Financial, and similarly, issue from entities not falling under the Italian mandatory disclosure rule. Is this a sign of opportunistic use of target prices in financial markets? Is there any differential accuracy by companies issuing from abroad and issuing domestically? Finally, despite the sizeable biases in forecasts, can we infer some information from target prices thus developing a profitable investment strategy? We leave these issues for future research. 


\section{REFERENCES}

Abdel-khalik R. and B. Aijnkya (1982), 'Returns to informational advantages: the case of analysts' forecast revisions', Accounting Review, Vol. 57, No. 4, pp. 661-680.

Asquith, P., M. B. Mikhail and A. S. Au (2005), 'Information Content of Equity Analyst Reports', Journal of Financial Economics, Vol. 75, No. 2, pp. 245-82.

Baker M., R. Greenwood and J. Wurgler (2009), “A catering theory of nominal prices', Journal of Finance, forthcoming.

Barber B., R. Lehavy, M. McNichols and B.Trueman (2001), 'Can Investors Profit from the Prophets? Security Analyst Recommendations and Stock Returns', Journal of Finance, Vol. 56, No. 2, pp. 531-63.

(2006), 'Buys, Holds, and Sells: The Distribution of Investment Banks' Stock Ratings and the Implication for the Profitability of Analysts' Recommendations', Journal of Accounting and Economics, Vol. 41, Nos. 1-2, pp. 87117.

Belcredi M., S. Bozzi, and S. Rigamonti, The impact of research reports on stock prices in Italy, Working Paper, 2003.

Beneish, M. (1991), 'Stock prices and the dissemination of analysts' recommendations', Journal of Business, Vol. 64, pp. 393-416.

Bernhardt D., M. Campello and E. Kutsoati (2004), 'Analyst Compensation and Forecast Bias', Working Paper No. 99-09, Tufts University.

(2006), 'Who Herds', Journal of Financial Economics, Vol. 80,

No. 3, pp. 657-675

Bjerring, J., J. Lakonishok and T. Vermaelen (1983), 'Stock prices and financial analysts' recommendations', Journal of Finance, Vol. 38, pp. 187-204.

Bradshaw, M. (2002), 'The use of target prices to justify sell-side analysts' stock recommendations', Accounting Horizons, Vol. 16, No. 1, pp. 27-41.

Bradshaw M. and L. Brown (2006), 'Do Sell-Side Analysts Exhibit Differential Target Price Forecasting Ability?', Working Paper, Harvard University. 
Brav, A. and R. Lehavy (2003), 'An empirical analysis of analysts' target prices: short term informativeness and long term dynamics', Journal of Finance, Vol. 58, pp 19331967.

Brown, L. and E. Mohd (2003), 'The Predictive Value of Analyst Characteristics', Journal of Accounting, Auditing and Finance, Vol. 18, No. 4, pp. 625-647.

Cervellati E.M. and A.C.F. Della Bina (2004), 'Analisti finanziari: conflitti di interesse o eccessivo ottimismo. Evidenza empirica dal mercato italiano delle IPO', Banca, Impresa e Società. XXIII, n. 2, pp.367-399, 2004.

Cooper, R.A. T. E. Day and C. M. Lewis (2001), 'Following the leader: a study of individual analysts' earnings forecasts', Journal of Financial Economics, Vol. 61, pp. 383-416.

Elton, E., M. Gruber and S. Grossman (1986), 'Discrete expectational data and portfolio performance', Journal of Finance, Vol. 41, pp. 699-713.

Falkenstein E. (1996), 'Preferences for stock characteristics as revealed by mutual fund portfolio holdings', The Journal of Finance, Vol. 51, No. 1, pp. 111-135.

Francis, J. and L. Soffer (1997), 'The Relative Informativeness of Analysts' Stock Recommendations and Earnings Forecast Revisions', Journal of Accounting Research, Vol. 35, No. 2, pp. 193-211.

Jegadeesh N., J. Kim, S. D. Krische and C. M. Lee (2004), 'Analyzing the Analysts: When Do Recommendations Add Value?', Journal of Finance, Vol. 59, No. 3, pp. 1083-124.

Johnson J. (2006), 'The Future of Equity Research: A 360 Perspective', TABB Group, available at: http://www.tabbgroup.com/our_reports.php?tabbaction=4\&reportId $=157$. Lloyd-Davies, P. and M. Canes (1978), 'Stock prices and the publication of secondhand information', Journal of Business, Vol. 51, pp. 43-56.

Liu, P., S. Smith and A. Syed (1990), 'Stock price reactions to the Wall Street Journal's securities recommendations', Journal of Financial and Quantitative Analysis, Vol. 25, pp. 399-410.

Lys, T. and S. Sohn (1990), 'The association between revisions of financial analysts' earnings forecasts and security price changes', Journal of Accounting and Economics, Vol 13, pp. 341-363. 
Michaely, R. and K. L.Womack (1999), 'Conflicts of Interest and the Credibility of Underwriter Analyst Recommendations', Review of Financial Studies, Vol. 12, No. 4, pp. $653-86$.

Ottaviani, M. and P. Sorensen, (2006), 'Reputational Cheap Talk', The Rand Journal of Economics, Vol 37, No. 1, pp. 155-175.

Ritter J. (2006), 'Security Analysts and Conflicts of Interest', Keynote Speech, 30th Journal of Banking and Finance Conference Proceedings, Beijing, China.

Stickel, S. (1990), 'Predicting Individual Analyst Earnings Forecasts', Journal of Accounting Research, Vol. 28, pp. 409-17.

Stickel, S.E. (1992), 'Reputation and Performance Among Security Analysts', Journal of Finance, Vol 47, pp. 1811-1836.

Stickel, S.E. (1995), 'The Anatomy of the Performance of Buy and Sell Recommendations', Financial Analysts Journal, Vol. 51, No. 5, pp. 25-39.

Welch I. (2000), 'Herding among security analysts', Journal of Financial Economics, Vol. 58, pp. 369-396.

Womack, K. L. (1996), 'Do Brokerage Analysts' Recommendations Have Investment Value?', Journal of Finance, Vol. 51, No. 1, pp. 137-67. 
TABLE 1

Database filtering and descriptive statistic of companies

The table shows descriptive statistics for the 10,939 reports issued on 98 companies included in the sample. Panel A report the sample cleaning procedure and the overall sample descriptive statistic. max number of reports identifies the largest number of reports issued on a single cpmpany and the relative percentage weight. Panel B reports the quintile distribution of reports and number of companies; Panel $\mathrm{C}$ reports the industry backgorund and associated descriptive statistics. Companies' industry classification is based on FTSE classification at level 3 .

PANEL A

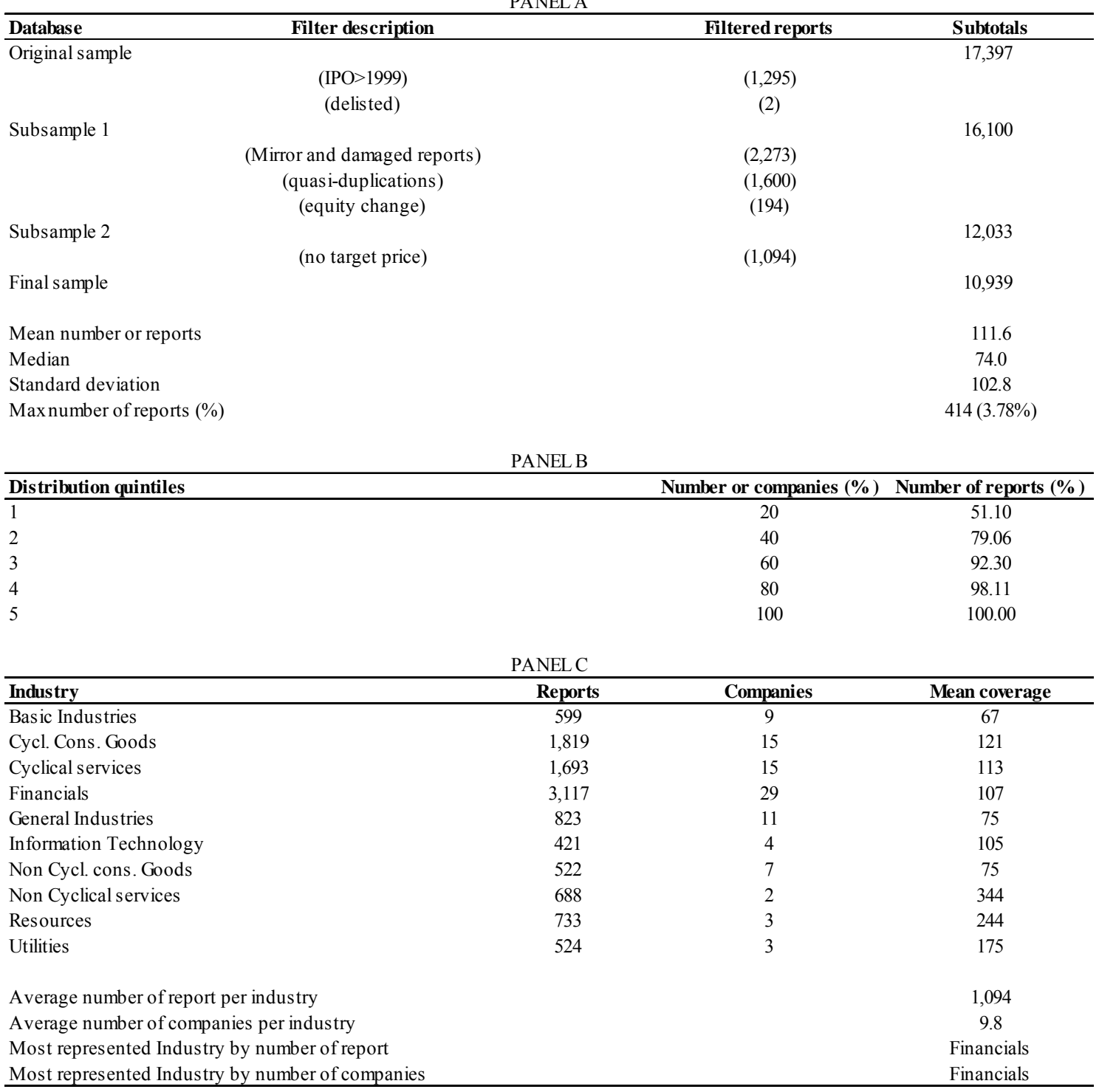


TABLE 2

\section{Yearly and monthly report distribution}

This table reports the sample breakdown by months, quarters, half-year and years and the reccomendation class distribution. Reports considered are all the reports included in the final database. Panel A, Column 1,2,and 3 report the absolute and percentage report distribution broken down by month, quarter and semester over the total number of reports issued in the six years sampling period. Columns four, five, six and seven report absolute distribution for each year. Panel B The first column reports absolute and percentage report distribution per recommendation class over the total number of reports issued. Columns two, three four and five report absolute distribution for each year. In both panels, percentage figures indicate the relative number of reports issued per recommendation class over the total number of reports issued each year.

\begin{tabular}{|c|c|c|c|c|c|c|c|c|c|c|}
\hline \multicolumn{11}{|c|}{ PANEL A } \\
\hline Month & Monthly & Quarterly & 6-months & 2000 & 2001 & 2002 & 2003 & 2004 & 2005 & 2006 \\
\hline January & $547(5.00 \%)$ & & & $29(3.54 \%)$ & $87(5.80 \%)$ & $42(2.53 \%)$ & $116(5.46 \%)$ & $90(4.82 \%)$ & $88(4.75 \%)$ & $95(8.54 \%)$ \\
\hline February & $1015(9.28 \%)$ & & & $72(8.78 \%)$ & $112(7.47 \%)$ & 97 (5.84\%) & $204(9.60 \%)$ & $213(11.40 \%)$ & $184(9.94 \%)$ & $133(11.96 \%)$ \\
\hline March & $1346(12.30 \%)$ & $2908(26.58 \%)$ & & $84(10.24 \%)$ & $198(13.20 \%)$ & $76(4.58 \%)$ & $264(12.42 \%)$ & $280(14.98 \%)$ & $278(15.01 \%)$ & $166(14.93 \%)$ \\
\hline April & $663(6.06 \%)$ & & & $42(5.12 \%)$ & $118(7.87 \%)$ & $73(4.39 \%)$ & $135(6.35 \%)$ & $127(6.80 \%)$ & $127(6.86 \%)$ & $41(3.69 \%)$ \\
\hline May & 1431 (13.08\%) & & & $110(13.41 \%)$ & $172(11.47 \%)$ & $139(8.37 \%)$ & $299(14.07 \%)$ & $285(15.25 \%)$ & $292(15.77 \%)$ & $134(12.05 \%)$ \\
\hline June & $530(4.85 \%)$ & 2624 (23.99\%) & $5532(50.57 \%)$ & $37(4.51 \%)$ & $75(5.00 \%)$ & $87(5.24 \%)$ & $95(4.47 \%)$ & $80(4.28 \%)$ & $112(6.05 \%)$ & $44(3.96 \%)$ \\
\hline July & $907(8.29 \%)$ & & & $56(6.83 \%)$ & $119(7.93 \%)$ & $186(11.20 \%)$ & $152(7.15 \%)$ & $175(9.36 \%)$ & $145(7.83 \%)$ & $74(6.65 \%)$ \\
\hline August & $542(4.95 \%)$ & & & $31(3.78 \%)$ & 77 (5.13\%) & $127(7.65 \%)$ & $105(4.94 \%)$ & $84(4.49 \%)$ & $78(4.21 \%)$ & $40(3.60 \%)$ \\
\hline September & $1467(13.41 \%)$ & 2916 (26.66\%) & & $114(13.90 \%)$ & $222(14.80 \%)$ & $275(16.56 \%)$ & $227(10.68 \%)$ & $268(14.34 \%)$ & $229(12.37 \%)$ & $132(11.87 \%)$ \\
\hline October & $752(6.87 \%)$ & & & $63(7.68 \%)$ & $137(9.13 \%)$ & $139(8.37 \%)$ & $143(6.73 \%)$ & $97(5.19 \%)$ & $103(5.56 \%)$ & $70(6.29 \%)$ \\
\hline November & $1349(12.33 \%)$ & & & $114(13.90 \%)$ & 137 (9.13\%) & $322(19.39 \%)$ & $298(14.02 \%)$ & $145(7.76 \%)$ & $181(9.77 \%)$ & $152(13.67 \%)$ \\
\hline December & $390(3.57 \%)$ & $2491(22.77 \%)$ & 5407 (49.43\%) & $68(8.29 \%)$ & $46(3.07 \%)$ & $98(5.90 \%)$ & $87(4.09 \%)$ & $25(1.34 \%)$ & $35(1.89 \%)$ & $31(2.79 \%)$ \\
\hline Total & $10939(100.00 \%)$ & $10939(100.00 \%)$ & $10939(100.00 \%)$ & $820(100.00 \%)$ & $1500(100.00 \%)$ & $1661(100.00 \%)$ & $2125(100.00 \%)$ & $1869(100.00 \%)$ & $1852(100.00 \%)$ & $1112(100.00 \%)$ \\
\hline \multicolumn{11}{|c|}{ PANEL B } \\
\hline \multicolumn{2}{|c|}{ Reccomendation Class } & Subtotal by class & & 2000 & 2001 & 2002 & 2003 & 2004 & 2005 & 2006 \\
\hline \multicolumn{2}{|c|}{ Strong buy } & $4299(39.30 \%)$ & & $346(42.20 \%)$ & $546(36.40 \%)$ & $675(40.64 \%)$ & $925(43.53 \%)$ & $729(39.00 \%)$ & $668(36.07 \%)$ & $410(36.87 \%)$ \\
\hline \multicolumn{2}{|l|}{ Buy } & 3795 (34.69\%) & & $191(23.29 \%)$ & $477(31.80 \%)$ & $559(33.65 \%)$ & $754(35.48 \%)$ & $665(35.58 \%)$ & $682(36.83 \%)$ & $467(42.00 \%)$ \\
\hline \multicolumn{2}{|l|}{ Hold } & $852(7.79 \%)$ & & $36(4.39 \%)$ & $141(9.40 \%)$ & $177(10.66 \%)$ & $205(9.65 \%)$ & $118(6.31 \%)$ & $152(8.21 \%)$ & $23(2.07 \%)$ \\
\hline \multicolumn{2}{|l|}{ Sell } & 1896 (17.33\%) & & $245(29.88 \%)$ & $319(21.27 \%)$ & $246(14.81 \%)$ & $232(10.92 \%)$ & 357 (19.10\%) & $298(16.09 \%)$ & 199 (17.90\%) \\
\hline \multicolumn{2}{|l|}{ Strong sell } & $97(0.89 \%)$ & & $2(0.24 \%)$ & $17(1.13 \%)$ & $4(0.24 \%)$ & $9(0.42 \%)$ & & $52(2.81 \%)$ & $13(1.17 \%)$ \\
\hline \multicolumn{2}{|l|}{ Total } & $10939(100.00 \%)$ & & $820(100.00 \%)$ & $1500(100.00 \%)$ & $1661(100.00 \%)$ & $2125(100.00 \%)$ & $1869(100.00 \%)$ & $1852(100.00 \%)$ & $1112(100.00 \%)$ \\
\hline
\end{tabular}


TABLE 3

\section{Stock recommendations transition matrix}

We present the absolute and relative stock recommendation transitions. For each initial recommendation class (FROM), we identified the revised recommendation (TO). Figures are then calculated as the ratio between the number of reports revised in the new recommendation class (TO) over the total number of reports of the initial recommendation class (FROM).

\begin{tabular}{|c|c|c|c|c|c|c|}
\hline \multirow[b]{2}{*}{$\underline{\text { TO }}$} & \multicolumn{6}{|c|}{ FROM } \\
\hline & Strong buy & Buy & Hold & Sell & Strong sell & TOTAL \\
\hline Strong buy & $1039(66.01 \%)$ & $448(12.30 \%)$ & $179(5.37 \%)$ & $25(3.37 \%)$ & $0(0.00 \%)$ & $1691(18.02 \%)$ \\
\hline Buy & $401(25.48 \%)$ & $2544(69.85 \%)$ & $695(20.84 \%)$ & $91(12.26 \%)$ & $2(2.20 \%)$ & $3733(39.78 \%)$ \\
\hline Hold & $120(7.62 \%)$ & $584(16.04 \%)$ & $2261(67.80 \%)$ & $217(29.25 \%)$ & $13(14.29 \%)$ & $3195(34.05 \%)$ \\
\hline Sell & $14(0.89 \%)$ & $66(1.81 \%)$ & $190(5.70 \%)$ & $392(52.83 \%)$ & $25(27.47 \%)$ & $687(7.32 \%)$ \\
\hline Strong sell & $0(0.00 \%)$ & $0(0.00 \%)$ & $10(0.30 \%)$ & $17(2.29 \%)$ & $51(56.04 \%)$ & $78(0.83 \%)$ \\
\hline TOTAL & $1574(100.00 \%)$ & $3642(100.00 \%)$ & $3335(100.00 \%)$ & $742(100.00 \%)$ & $91(100.00 \%)$ & $9384(100.00 \%)$ \\
\hline
\end{tabular}


TABLE 4

\section{Reports accuracy summary statistics}

This table shows summary statistics for implicit returns, target price revisions and accuracy metrics. In Column 1 we report predicted implicit returns computed as the difference between target price and the market price at the issue date. In Column 2 we report the quantitative change in Target Price revisions measured as the percentage difference between a target price and its closest revision. Columns 3 and 4 report figures for the binary metric introduced by Bradshaw and Brown (2006), to allow comparis on with previous studies. TPmetANY indicates the percentage of reports for which the market price reaches the target price at any point during the TP prediction window. TPmetEND indicates the percentage of reports for which the market price has reached the TP at the end of th TP prediction window. Columns 5 and 6 report figures for the Ideal Strategy (IS) accuracy control metric and variable respectively. Columns 5 and 6 report figures for the Feasible Strategy (FS) accuracy control metric and variable respectively

\begin{tabular}{|c|c|c|c|c|c|c|c|c|}
\hline & {$\left[\mathbf{T P}_{\mathrm{t}} / \mathbf{P}_{\mathrm{t}}\right]-1$} & {$\left[T P_{t+n} / T P_{t}\right]-1$} & TPmetANY & TPmetEND & $\delta_{1}$ & $\delta_{2}$ & $\delta_{3}$ & $\delta_{4}$ \\
\hline \multicolumn{9}{|l|}{ Strong buy } \\
\hline Mean & $36.93 \% * * *$ & $5.31 \% * * *$ & $11.61 \%$ & $7.32 \%$ & $13.54 \% * * *$ & $22.26 \% * * *$ & $2.97 \% * * *$ & $36.85 \% * * *$ \\
\hline Median & $28.62 \%$ & $0.00 \%$ & & & $7.60 \%$ & $18.72 \%$ & $1.79 \%$ & $26.82 \%$ \\
\hline Std. Dev. & $55.04 \%$ & $36.73 \%$ & $32.41 \%$ & $26.33 \%$ & $18.39 \%$ & $50.27 \%$ & $21.53 \%$ & $58.63 \%$ \\
\hline N. of obser. & 1896 & 1574 & 1896 & 1896 & \multicolumn{4}{|c|}{1896} \\
\hline \multicolumn{9}{|l|}{ Buy } \\
\hline Mean & $19.25 \% * * *$ & $7.48 \% * * *$ & $25.51 \%$ & $15.14 \%$ & $13.19 \% * * *$ & $6.98 \% * * *$ & $2.96 \% * * *$ & $20.52 \% * * *$ \\
\hline Median & $16.53 \%$ & $0.00 \%$ & & & $7.61 \%$ & $8.11 \%$ & $1.52 \%$ & $14.97 \%$ \\
\hline Std. Dev. & $12.86 \%$ & $111.93 \%$ & $43.35 \%$ & $35.67 \%$ & $18.71 \%$ & $15.37 \%$ & $20.44 \%$ & $31.07 \%$ \\
\hline N. of obser. & 4295 & 3642 & 4295 & 4295 & \multicolumn{4}{|c|}{4295} \\
\hline \multicolumn{9}{|l|}{ Hold } \\
\hline Mean & $5.73 \% * * *$ & $2.61 \%$ & $50.62 \%$ & $30.71 \%$ & $7.03 \% * * *$ & $-3.37 \% * * *$ & $2.00 \% * * *$ & $9.58 \% * * *$ \\
\hline Median & $5.00 \%$ & $0.00 \%$ & & & $3.58 \%$ & $-0.12 \%$ & $0.69 \%$ & $6.15 \%$ \\
\hline Std. Dev. & $12.67 \%$ & $85.48 \%$ & $50.01 \%$ & $46.07 \%$ & $20.39 \%$ & $21.52 \%$ & $21.94 \%$ & $29.62 \%$ \\
\hline N. of obser. & 3795 & 3336 & 3795 & 3795 & \multicolumn{4}{|c|}{3795} \\
\hline \multicolumn{9}{|l|}{ Sell } \\
\hline Mean & $-9.92 \% * * *$ & $-8.76 \% * * *$ & $46.34 \%$ & $27.94 \%$ & $-9.93 \% * * *$ & $-8.99 \% *$ & $-0.56 \% * * *$ & $6.99 \% * * *$ \\
\hline Median & $-9.86 \%$ & $-2.67 \%$ & & & $-6.25 \%$ & $1.50 \%$ & $-0.95 \%$ & $11.52 \%$ \\
\hline Std. Dev. & $13.20 \%$ & $34.67 \%$ & $49.91 \%$ & $44.78 \%$ & $21.60 \%$ & $46.27 \%$ & $24.92 \%$ & $41.90 \%$ \\
\hline N. of obser. & 852 & 743 & 852 & 852 & \multicolumn{4}{|c|}{852} \\
\hline \multicolumn{9}{|l|}{ Strong Sell } \\
\hline Mean & $-31.99 \% * * *$ & $20.62 \% * * *$ & $15.29 \%$ & $7.06 \%$ & $-10.74 \% * * *$ & $19.75 \% * * *$ & $-0.43 \% * * *$ & $29.14 \% * * *$ \\
\hline Median & $-29.37 \%$ & $0.00 \%$ & & & $-6.01 \%$ & $24.29 \%$ & $-1.04 \%$ & $31.94 \%$ \\
\hline Std. Dev. & $15.15 \%$ & $229.92 \%$ & $36.34 \%$ & $26.01 \%$ & $14.83 \%$ & $32.77 \%$ & $20.04 \%$ & $24.21 \%$ \\
\hline N. of obser. & 97 & 91 & 97 & 97 & \multicolumn{4}{|c|}{97} \\
\hline TOTAL & & & $33.12 \%$ & $20.00 \%$ & & & & \\
\hline
\end{tabular}


TABLE 5

Prediction errors analysis

This table shows mean prediction erros by analyst and results for tests on the autoregressive component in analysts prediction errors. For each bank we have run the following regressions $\mathrm{Y}_{\mathrm{t}}=\alpha+\beta \mathrm{Y}_{\mathrm{t}-\mathrm{n}}+\varepsilon$ where $\alpha$ is the intercept capturing the stationary component in prediction errors and $\beta$ is the parameter capturing the autoregression component on a the lagged variable $\mathrm{Y}_{\mathrm{t}-\mathrm{n}}$. We run regression for 1, 2 and 3 lags. For each variable, the first column reports the average prediction error, the second column reports the lag for which the autoregression component was most significant, the third column presents the the value of the intercept of the AR(n) regression and the fourth column the the value of the estimated AR(n)parameter. Significance at $10 \%, 5 \%$ and $1 \%$ level is denoted by $* * *, * * *$ respectively.

\begin{tabular}{|c|c|c|c|c|c|c|c|c|c|}
\hline \multirow[b]{3}{*}{ Firm } & \multirow[b]{3}{*}{ Obs } & \multicolumn{4}{|c|}{$\delta_{2}$} & \multicolumn{4}{|c|}{$\delta 4$} \\
\hline & & \multirow[b]{2}{*}{ Average } & \multicolumn{3}{|c|}{ AR(n) Regressions } & \multirow[b]{2}{*}{ Average } & \multicolumn{3}{|c|}{ AR(n) Regressions } \\
\hline & & & $\overline{\mathrm{AR}}$ & Intercept & AR Coefficient & & $\mathrm{AR}$ & Intercept & AR Coefficient \\
\hline Abaxbank & 72 & $-0.058 * * *$ & 1 & $-0.060 * * *$ & -0.030 & 0.043 & 2 & 0.035 & $0.019 * *$ \\
\hline ABN AMRO & 95 & -0.037 & 2 & -0.031 & 0.125 & $0.114 * * *$ & 1 & $0.095 * * *$ & 0.148 \\
\hline Actinvest & 238 & 0.017 & 1 & 0.013 & $0.272 * * *$ & $0.302 * * *$ & 2 & $0.262 * * *$ & $0.126^{* *}$ \\
\hline Axia & 47 & -0.026 & 1 & -0.026 & 0.113 & $0.095 * * *$ & 1 & $0.076^{* *}$ & 0.166 \\
\hline Banca Aletti & 53 & $0.046^{* *}$ & 1 & 0.033 & $0.276^{* *}$ & $0.126^{* * *}$ & 1 & $0.076^{* *}$ & $0.365^{* * *}$ \\
\hline Banca Finnat & 12 & 0.035 & 1 & 0.021 & -0.365 & $0.127^{* *}$ & 1 & $0.164 * *$ & -0.465 \\
\hline Banca Leonardo & 606 & $0.048 * * *$ & 2 & $0.035^{* * *}$ & $0.272 * * *$ & $0.154 * * *$ & 2 & $0.140 * * *$ & $0.086^{* * *}$ \\
\hline Banca Mediosim & 1 & 0.506 & 1 & & & 1.113 & 1 & & \\
\hline Banca Sella & 7 & -0.031 & 2 & -0.134 & 0.256 & $0.737^{*}$ & 1 & $1.256^{* *}$ & -0.672 \\
\hline Banknord & 7 & $0.213 * * *$ & 1 & $0.270^{*}$ & -0.126 & $0.510 * * *$ & 1 & 0.640 & -0.215 \\
\hline Bipielle/Santander & 113 & $0.050^{* *}$ & 1 & $0.035^{*}$ & $0.273 * * *$ & $0.243 * * *$ & 1 & $0.192 * * *$ & $0.187^{* *}$ \\
\hline BNP Paribas/Exane & 126 & -0.006 & 1 & -0.004 & -0.047 & $0.167 * * *$ & 2 & $0.134 * * *$ & $0.158^{*}$ \\
\hline BP Bari & 2 & -0.168 & 1 & & & 0.065 & 1 & & \\
\hline BPM & 580 & $0.039 * * *$ & 1 & $0.032 * * *$ & $0.197 * * *$ & $0.160 * * *$ & 1 & $0.120 * * *$ & $0.250 * * *$ \\
\hline Cazenove & 25 & 0.029 & 1 & 0.037 & -0.176 & $0.075^{*}$ & 1 & $0.094 * *$ & -0.214 \\
\hline Centrosim & 314 & $0.070 * * *$ & 1 & $0.068 * *$ & 0.032 & $0.173 * * *$ & 1 & $0.122 * * *$ & $0.295 * * *$ \\
\hline Cheuvreux & 231 & -0.023 & 1 & -0.022 & 0.036 & $0.235 * * *$ & 1 & $0.233 * * *$ & 0.012 \\
\hline Citigroup & 197 & $0.095 * * *$ & 1 & $0.090 * * *$ & 0.074 & $0.164 * * *$ & 1 & $0.156^{* * *}$ & 0.058 \\
\hline Cofiri & 38 & 0.005 & 1 & 0.011 & -0.128 & $0.162 * * *$ & 2 & $0.107^{* *}$ & $0.259^{*}$ \\
\hline Consors & 30 & -0.025 & 1 & -0.024 & 0.155 & $0.380 * * *$ & 1 & $0.379 * * *$ & -0.044 \\
\hline Credit Agricole & 1 & -0.078 & 1 & & & -0.065 & 1 & & \\
\hline Credit Lyonnais & 36 & -0.059 & 1 & $-0.077^{*}$ & -0.214 & $0.186^{* *}$ & 2 & $0.159 *$ & 0.184 \\
\hline CSFB & 138 & 0.012 & 1 & 0.012 & 0.009 & $0.165^{* * *}$ & 1 & $0.118 * * *$ & $0.270 * * *$ \\
\hline Deutsche Bank & 740 & $0.083 * * *$ & 1 & $0.062 * * *$ & $0.253 * * *$ & $0.183 * * *$ & 1 & $0.152 * * *$ & $0.174 * * *$ \\
\hline DKW & 121 & -0.049 & 1 & -0.049 & 0.010 & $0.241 * * *$ & 2 & $0.185^{* * *}$ & $0.159^{*}$ \\
\hline Eptasim & 124 & -0.058 & 2 & -0.057 & 0.059 & $0.171 * * *$ & 1 & $0.176^{* * *}$ & -0.053 \\
\hline Euromobiliare & $1,075.00$ & $0.098 * * *$ & 1 & $0.065 * * *$ & $0.337 * * *$ & $0.217 * * *$ & 1 & $0.149 * * *$ & $0.313 * * *$ \\
\hline Fortis bank & 24 & 0.010 & 1 & 0.016 & -0.162 & $0.290 * * *$ & 1 & $0.391 * * *$ & -0.295 \\
\hline Gestnord & 2 & 0.000 & 1 & & & 0.636 & 1 & & \\
\hline Goldman Sachs & 92 & $0.042 * * *$ & 2 & $0.036 * * *$ & $0.177^{*}$ & $0.092 * * *$ & 1 & $0.106 * * *$ & -0.125 \\
\hline Ideaglobal & 137 & $-0.071 * *$ & 1 & $-0.062 * *$ & $0.137^{*}$ & $0.142 * * *$ & 1 & $0.141 * * *$ & 0.012 \\
\hline IMI & 361 & $0.079 * * *$ & 1 & $0.045^{* *}$ & $0.424 * * *$ & $0.271 * * *$ & 1 & $0.264 * * *$ & 0.026 \\
\hline ING & 172 & 0.000 & 1 & -0.001 & $0.166^{* *}$ & $0.093 * * *$ & 1 & $0.070 * * *$ & $0.206 * * *$ \\
\hline Interbanca & 5 & -0.036 & 1 & -0.058 & -0.524 & 0.074 & 1 & 0.128 & -0.635 \\
\hline Intermonte & 1316 & $0.055^{* * *}$ & 1 & $0.046^{* * *}$ & $0.169^{* * *}$ & $0.172 * * *$ & 1 & $0.148 * * *$ & $0.140 * * *$ \\
\hline Intesa & 610 & $0.051 * * *$ & 1 & $0.031 * *$ & $0.398 * * *$ & $0.191 * * *$ & 1 & $0.169 * * *$ & $0.119 * * *$ \\
\hline JP Morgan & 26 & $-0.040 * *$ & 1 & -0.023 & 0.253 & 0.009 & 1 & 0.019 & 0.020 \\
\hline Julius Baer/Kepler & 243 & 0.012 & 1 & 0.010 & 0.080 & $0.255 * * *$ & 2 & $0.229 * * *$ & 0.101 \\
\hline Lehman Brothers & 223 & $0.065 * * *$ & 1 & $0.054 * * *$ & $0.170 * * *$ & $0.129 * * *$ & 1 & $0.107 * * *$ & $0.172 * * *$ \\
\hline M. Mortari & 60 & $0.128 * *$ & 1 & 0.044 & $0.404 * * *$ & $0.302 * * *$ & 1 & $0.143^{* *}$ & $0.414 * * *$ \\
\hline Mediobanca & 368 & $0.097 * * *$ & 1 & 0.030 & $0.696^{* * *}$ & $0.187 * * *$ & 1 & $0.071 * * *$ & $0.624 * * *$ \\
\hline Merrill Lynch & 417 & $0.076^{* * *}$ & 1 & $0.069 * * *$ & $0.087^{*}$ & $0.195 * * *$ & 1 & $0.146 * * *$ & $0.255^{* * *}$ \\
\hline Metzler & 14 & $0.033 * * *$ & 1 & 0.016 & 0.025 & $0.465 * * *$ & 1 & $0.435^{* *}$ & -0.084 \\
\hline Morgan Stanley & 2 & 0.020 & 1 & & & 0.205 & 1 & & \\
\hline Rasfin & 426 & $0.045^{* * *}$ & 1 & $0.044 * * *$ & 0.028 & $0.192 * * *$ & 2 & $0.172 * * *$ & $0.103^{* *}$ \\
\hline SG & 99 & $-0.032 * * *$ & 1 & -0.026 & 0.079 & $0.232 * * *$ & 1 & $0.220 * * *$ & 0.066 \\
\hline UBM & 794 & $0.064 * * *$ & 1 & $0.049 * * *$ & $0.243^{* * *}$ & $0.173 * * *$ & 1 & $0.127 * * *$ & $0.267 * * *$ \\
\hline UBS & 510 & $0.015 * * *$ & 1 & 0.014 & $0.078^{*}$ & $0.153 * * *$ & 1 & $0.139 * * *$ & $0.094 * *$ \\
\hline Uniprof & 9 & -0.101 & 1 & -0.013 & 0.030 & 0.071 & 1 & $0.173 *$ & $-0.480^{*}$ \\
\hline Full Sample & 10939 & $0.049 * * *$ & 1 & $0.036^{* * *}$ & $0.277 * * *$ & $0.186^{* * *}$ & 1 & $0.152 * * *$ & $0.178 * * *$ \\
\hline
\end{tabular}


TABLE 6

\section{Accuracy and research intensity}

We test the effect of research intensity on analysts' accuracy. Column 1 and 2 show estimates obtained by regressing each firm yearly average $\delta_{2}$ and $\delta_{4}$ accuracy measure on the natural logarithm of the total amount of reports published by the firm in every sample year. Column 3 shows estimates obtained by regressing the average yearly volatility of implicit returns $\left(\mathrm{TP}_{\mathrm{t}, \mathrm{j}, \mathrm{i}} / \mathrm{P}_{\mathrm{t}, \mathrm{j}}\right)$ embedded in target prices issued by each firm on the number of reports published yearly by each bank. Significance at $10 \%, 5 \%$ and $1 \%$ level is denoted by $*, * *, * * *$ respectively.

\begin{tabular}{|c|c|c|c|c|c|c|}
\hline \multirow[b]{2}{*}{ Dependent Variable } & \multicolumn{2}{|c|}{$\bar{\delta}_{2, i}$} & \multicolumn{2}{|l|}{$\bar{\delta}_{4, i}$} & \multicolumn{2}{|c|}{ Implicit return volatility } \\
\hline & Coefficient & T-stat & Coefficient & T-stat & Coefficient & T-stat \\
\hline Intercept & -0.020 & -1.08 & $0.230 * * *$ & 7.91 & $0.013 * * *$ & 2.92 \\
\hline $\mathrm{N}^{\circ}$ report & $0.016 * * *$ & 2.89 & -0.008 & -0.94 & $0.201 * * *$ & 9.50 \\
\hline $\operatorname{Adj} R^{2}$ & 0.035 & & 0.004 & & 3.70 & \\
\hline Std. Error of Es timate & 0.017 & & 0.039 & & 0.152 & \\
\hline F-Statistic & $8.380 * * *$ & & 0.890 & & $3.700 * * *$ & \\
\hline Observations & 236 & & 236 & & 236 & \\
\hline
\end{tabular}




\section{TABLE 7}

Accuracy measures and recommendation classes

This table provides evidence on the effect on prediction errors of each recommendation class controlling for the Implicit return effect. We regress $\delta_{2, \mathrm{j}, \mathrm{i}}$ and $\delta_{4, \mathrm{j}, \mathrm{i}}$ on 4 dummy variables representing the recommendation classes 'Strong Buy, 'Buy', 'Sell', 'Strong Sell' and on one variable ( $\left.\left(\mathrm{TP}_{\mathrm{t}, \mathrm{j}, \mathrm{i}} / \mathrm{P}_{\mathrm{t}, \mathrm{j}}\right)-1\right)$ representing the implicit return in target prices at the time of report publication. We exclude the 'Hold' class which is our control class. Significance at $10 \%, 5 \%$ and $1 \%$ level is denoted by $*, * *, * * *$ respectively.

\begin{tabular}{|c|c|c|c|c|}
\hline \multirow[b]{2}{*}{ Dependent Variable } & \multicolumn{2}{|c|}{$\delta_{2, \mathrm{j}, \mathrm{i}}$} & \multicolumn{2}{|c|}{$\delta_{4, \mathrm{j}, \mathrm{i}}$} \\
\hline & Coefficient & T-stat & Coefficient & T-stat \\
\hline Intercept & -0.079 & 0.003 & $0.061 * * *$ & 10.82 \\
\hline$\left(\mathrm{TP}_{\mathrm{t}, \mathrm{j}, \mathrm{i}} / \mathrm{P}_{\mathrm{t}, \mathrm{j}}\right)-1$ & $0.789 * * *$ & 99.37 & $0.612 * * *$ & 48.04 \\
\hline Strong buy & 0.010 & 1.55 & $0.082 * * *$ & 7.84 \\
\hline Buy & -0.003 & -0.67 & $0.027 * * *$ & 3.41 \\
\hline Sell & $0.067 * * *$ & 8.21 & $0.070 * * *$ & 5.32 \\
\hline Strong sell & $0.529 * * *$ & 23.87 & $0.427 * * *$ & 12 \\
\hline $\operatorname{Adj} R^{2}$ & 0.526 & & 0.228 & \\
\hline Std. Error of Estimate & 0.214 & & 0.343 & \\
\hline F-Statistic (Significance Level) & $2,429.1 * * *$ & & $646.1 * * *$ & \\
\hline Observations & 10939 & & 10939 & \\
\hline
\end{tabular}


TABLE 8

Accuracy measures and recommendation revisions

In this table we test the effect on accurcay by recommendation revisions controlling for the implicit return effect. We regress $\delta_{2, \mathrm{j}, \mathrm{i}}$ and $\delta_{4, \mathrm{j}, \mathrm{i}}$ on 2 dummy variables representing the recommendation revision types 'upgrade' and 'downgrade' and on one variable representing the implicit return $\left(\mathrm{TP}_{\mathrm{t}, \mathrm{j}, \mathrm{i}} / \mathrm{P}_{\mathrm{t}, \mathrm{j}}\right)-1$ in target prices at the time of report publication. We exclude the 'reiteration' class which is our control class. Significance at $10 \%, 5 \%$ and $1 \%$ level is denoted by $*, * *, * * *$ respectively.

\begin{tabular}{lccccc}
\hline & \multicolumn{2}{c}{$\delta_{2, \mathrm{j}, \mathrm{i}}$} & & \multicolumn{2}{c}{$\delta_{4, \mathrm{j}, \mathrm{i}}$} \\
\cline { 2 - 3 } \cline { 5 - 6 } Dependent Variable & Coefficient & T-stat & & Coefficient & T-stat \\
\hline Intercept & $-0.813^{* * *}$ & 103.970 & & $-0.514^{* * *}$ & -39.790 \\
$\left(\mathrm{TP}_{\mathrm{t}, \mathrm{j}, \mathrm{i}} / \mathrm{P}_{\mathrm{t}, \mathrm{j}}\right)-1$ & $0.758^{* * * *}$ & -2.210 & & $0.597^{* * *}$ & 55.860 \\
Upgrade & $-0.014^{* *}$ & 1.900 & & -0.003 & -0.380 \\
Downgrade & $0.011^{* * *}$ & -92.300 & & $0.030^{* * *}$ & 3.510 \\
& & & & \\
Adj $\mathrm{R}^{2}$ & 0.539 & & & 0.251 & \\
Std. Error of Estimate & 0.212 & & & 0.31 \\
F-Statistic (Significance Level) & $3,656.0^{* * *}$ & & & $1,049.4^{* * *}$ \\
Observations & 9377 & & & & \\
\hline
\end{tabular}




\section{TABLE 9}

\section{Accuracy and market factors}

This table provides results from regressing $\delta_{2, \mathrm{j}, \mathrm{i}}$ and $\delta_{4, \mathrm{j}, \mathrm{i}}$ errors on 7 variables related to: company status, market momentum and research intensity. Variables are defined as follows: (TPt,j, $/ \mathrm{Pt}, \mathrm{j})-1$ is the expected implicit return measured by the ratio between the target price and the share market price at $t$; (MV) is the natural logarithm of the forecasted company market value measured at each report issuing date as the stock market capitalization in million euro; (COV. RATIO) is the research intensity measured by the company coverage ratio calculated as the number of reports issued on company $i$ divided by total number of reports issued; (VOL) is the volume of share transaction calculated at each recommendation issuing day as the average turnaround volume measured in million euro; (MIB30) is a dummy variable taking a value of 1 if, at the report issue date, the company is included in the Large Cap index; (MOMENTUM) is measured as the relative level of the market index at any report issuing date, divided by the average index value between 2000 and 2006; MKTRET captures the market return for each TP's forecasting period. Significance at $10 \%, 5 \%$ and $1 \%$ level is denoted by $* * *, * * *$ respectively.

\begin{tabular}{|c|c|c|c|c|}
\hline \multirow[b]{2}{*}{ Dependent Variable } & \multicolumn{2}{|c|}{$\delta_{2, \mathrm{j}, \mathrm{i}}$} & \multicolumn{2}{|c|}{$\delta_{4, \mathrm{j}, \mathrm{i}}$} \\
\hline & Coefficient & T-stat & Coefficient & T-stat \\
\hline Intercept & $-0.890 * * *$ & -25.94 & $-0.476 * * *$ & -4.14 \\
\hline$\left(T P_{t, j, i} / P_{t, j}\right)-1$ & $0.762 * * *$ & 30.46 & $0.619 * * *$ & 6.05 \\
\hline MV & $0.009 * * *$ & 5.66 & 0.002 & 0.75 \\
\hline COV. RATIO & $0.528 * * *$ & 8.57 & $-0.006^{*}$ & -0.07 \\
\hline MOMENTUM & $0.006^{* * *}$ & 6.86 & $-0.005 * * *$ & -2.31 \\
\hline EPS & $-0.026 * *$ & -2.2 & $-0.092 * * *$ & -5.29 \\
\hline $\mathrm{P} / \mathrm{B}$ & $-0.005 * * *$ & -2.76 & $0.011 * * *$ & 3.17 \\
\hline MKTRET & $0.047 * * *$ & 2.95 & $-0.334 * * *$ & -12.92 \\
\hline Industry F.E, & YES & & YES & \\
\hline $\operatorname{Adj} R^{2}$ & 0.518 & & 0.268 & \\
\hline Std. Error of Estimate & 0.215 & & 0.334 & \\
\hline F-Statistic (Significance Level) & $157.680 * * *$ & & $84.780 * * *$ & \\
\hline Observations & 10939 & & 10939 & \\
\hline
\end{tabular}


TABLE 10

\section{Partial pre diction error regression}

This table provides results from regressing $\delta_{2, \mathrm{j}, \mathrm{i}}$ and $\delta_{4, \mathrm{j}, \mathrm{i}}$ partial errors previously sorted by 3 stock recommendations groups: Strong buy-Buy, Hold, Sell-Strong Sell and by 2 groups of sign of errors :

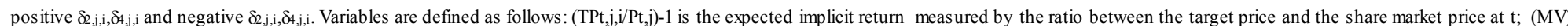
is the natural logarithm of the forecasted company market value measured at each report issuing date as the stock market capitalization in million euro; (COV. RATIO) is the research intensity measured by the company coverage ratio calculated as the number of reports issued on company i divided by total number of reports issued; (VOL) is the volume of share transaction calculated at each recommendation issuing day as the average turnaround volume measured in million euro; (MIB30) is a dummy variable taking a value of 1 if, at the report issue date, the company is included in the Large Cap index; (MOMENTUM) is measured as the relative level of the market index at any report issuing date, divided by the average index value between 2000 and 2006; MKTRET captures the market return for each TP's forecasting period. Panel A and B reports results for the $\delta_{2}$ and $\delta_{4}$ accuracy metric respectively. Significance at $10 \%, 5 \%$ and $1 \%$ level is denoted by *,**,*** respectively.

\begin{tabular}{|c|c|c|c|c|c|c|c|c|c|c|}
\hline \multirow[b]{3}{*}{ Dependent Variable } & \multicolumn{6}{|c|}{ PANEL A } & & & & \\
\hline & \multicolumn{2}{|c|}{ (StrongBuy-Buy) } & \multicolumn{2}{|c|}{ (Hold) } & \multicolumn{2}{|c|}{ (StrongSell-Sell) } & \multicolumn{2}{|c|}{$\delta 2, \mathrm{j}, \mathrm{i}>0$} & \multicolumn{2}{|c|}{$\delta 2, \mathrm{j}, \mathrm{i}<0$} \\
\hline & Coefficient & T-stat & Coefficient & T-stat & Coefficient & T-stat & Coefficient & T-stat & Coefficient & T-stat \\
\hline Intercept & $-0.213^{* * *}$ & -14.40 & $-0.140^{* * * *}$ & -5.49 & $0.530^{* * *}$ & 11.59 & $0.087 * * *$ & 6.74 & $-0.429 * * *$ & -11.23 \\
\hline MV & $0.012^{* * *}$ & 8.75 & $0.008 * * *$ & 3.33 & $0.019 *$ & 1.77 & -0.002 & -1.42 & $0.020^{* * *}$ & 6.28 \\
\hline COV. RATIO & $0.508^{* * *}$ & 9.85 & $0.386^{* *}$ & 2.97 & $1.071^{* * *}$ & 3.77 & 0.009 & 0.24 & $0.737 * * *$ & 5.20 \\
\hline MOMENTUM & $0.006 * * *$ & 8.11 & $0.003 * * *$ & 1.99 & 0.006 & 1.25 & $0.005 * * *$ & 6.22 & $0.004 * * *$ & 2.29 \\
\hline EPS & -0.011 & -1.29 & -0.004 & -0.27 & $0.131^{* *}$ & 2.53 & $-0.061 * * *$ & -8.30 & $0.078 * * *$ & 2.85 \\
\hline Indystry F.E. & YES & & YES & & YES & & YES & & YES & \\
\hline $\operatorname{Adj} R^{2}$ & 0.8151 & & 0.1185 & & 0.1754 & & 0.7778 & & 0.1149 & \\
\hline Std. Error of Estimate & 0.1351 & & 0.20211 & & 0.41679 & & 0.12816 & & 0.26825 & \\
\hline F-Statistic (Significance Level) & $282.630^{* * * *}$ & & $21.780^{* * * *}$ & & $13.610^{* * *}$ & & $121.540^{* * *}$ & & $16.850^{* * *}$ & \\
\hline Observations & 6187 & & 3790 & & 948 & & 7208 & & 3619 & \\
\hline
\end{tabular}

PANEL B

\begin{tabular}{|c|c|c|c|c|c|c|c|c|c|c|}
\hline \multirow[b]{2}{*}{ Dependent Variable } & \multicolumn{2}{|c|}{ (StrongBuy-Buy) } & \multicolumn{2}{|c|}{ (Hold) } & \multicolumn{2}{|c|}{ (StrongSell-Sell) } & \multicolumn{2}{|c|}{$\delta 4, \mathrm{j}, \mathrm{i}>0$} & \multicolumn{2}{|c|}{$\delta 4, \mathrm{j}, \mathrm{i}<0$} \\
\hline & Coefficient & T-stat & Coefficient & T-stat & Coefficient & T-stat & Coefficient & T-stat & Coefficient & T-stat \\
\hline$\left(\mathrm{TP}_{\left.\mathrm{t}, \mathrm{j}, \mathrm{j} / \mathrm{P}_{\mathrm{t}, \mathrm{j}}\right)-1}\right.$ & $0.626^{* * * *}$ & 4.61 & $0.707 * * *$ & 12.32 & $-0.303 * *$ & -2.39 & $0.536^{* * *}$ & 4.93 & $0.391 * * *$ & 6.39 \\
\hline MV & 0.003 & 0.85 & 0.004 & 1.13 & 0.002 & 0.21 & $-0.007 * *$ & -2.35 & $0.007 *$ & 2.00 \\
\hline MOMENTUM & $-0.008 * * *$ & -2.57 & -0.003 & -1.52 & -0.001 & -0.24 & $-0.006 * * *$ & -2.22 & $-0.007 * * *$ & -3.38 \\
\hline EPS & $-0.131 * * *$ & -5.23 & $-0.074 * * *$ & -3.44 & $0.079^{* *}$ & 1.55 & $-0.146^{* * * *}$ & -8.26 & 0.037 & 1.27 \\
\hline $\mathrm{P} / \mathrm{B}$ & $0.025 * * *$ & 4.14 & 0.003 & 1.24 & $-0.013 * * *$ & -1.93 & $0.019^{* * *}$ & 4.13 & 0.007 & 1.19 \\
\hline MKTRET & $-0.456 * * *$ & -14.12 & $-0.292 * * *$ & -6.64 & $0.437^{* * *}$ & 3.57 & $-0.457 * * *$ & -17.21 & 0.016 & 0.34 \\
\hline $\operatorname{Adj} R^{2}$ & 0.3599 & & 0.1428 & & 0.0784 & & 0.3531 & & 0.0347 & \\
\hline Std. Error of Estimate & 0.3375 & & 0.27422 & & 0.39352 & & 0.30801 & & 0.312 & \\
\hline F-Statistic (Significance Level) & $109.980^{* * *}$ & & $39.020^{* * * *}$ & & $4.900^{* * * *}$ & & $136.430^{* * * *}$ & & $11.850^{* * * *}$ & \\
\hline Observations & 6187 & & 3790 & & 948 & & 7208 & & 3619 & \\
\hline
\end{tabular}




\section{FIGURE 1}

Accuracy metrics

We graphically present the four accuracy measures we developed in this paper. $\delta_{1}$ is defined as the 'Ideal Strategy' (IS) control variable which calculates the ideal return as the difference between the maximum/minimum price over the time horizon and the issue date share price. $\delta_{2}$ measures the IS prediction error for any report as the difference between the issued target price at t0 and the maximum/(minimum) market price in the relevant prediction time-horizon. $\delta_{3}$ is the second control variable mea suring the 'Fea sible Strategy' (FS) return as the difference between the price at the end of the time horizon and the report's issue date share price. $\delta_{4}$ measures the FS prediction error for any report as the difference between the issued target price and the stock market price at the end of the investment time-horizon.

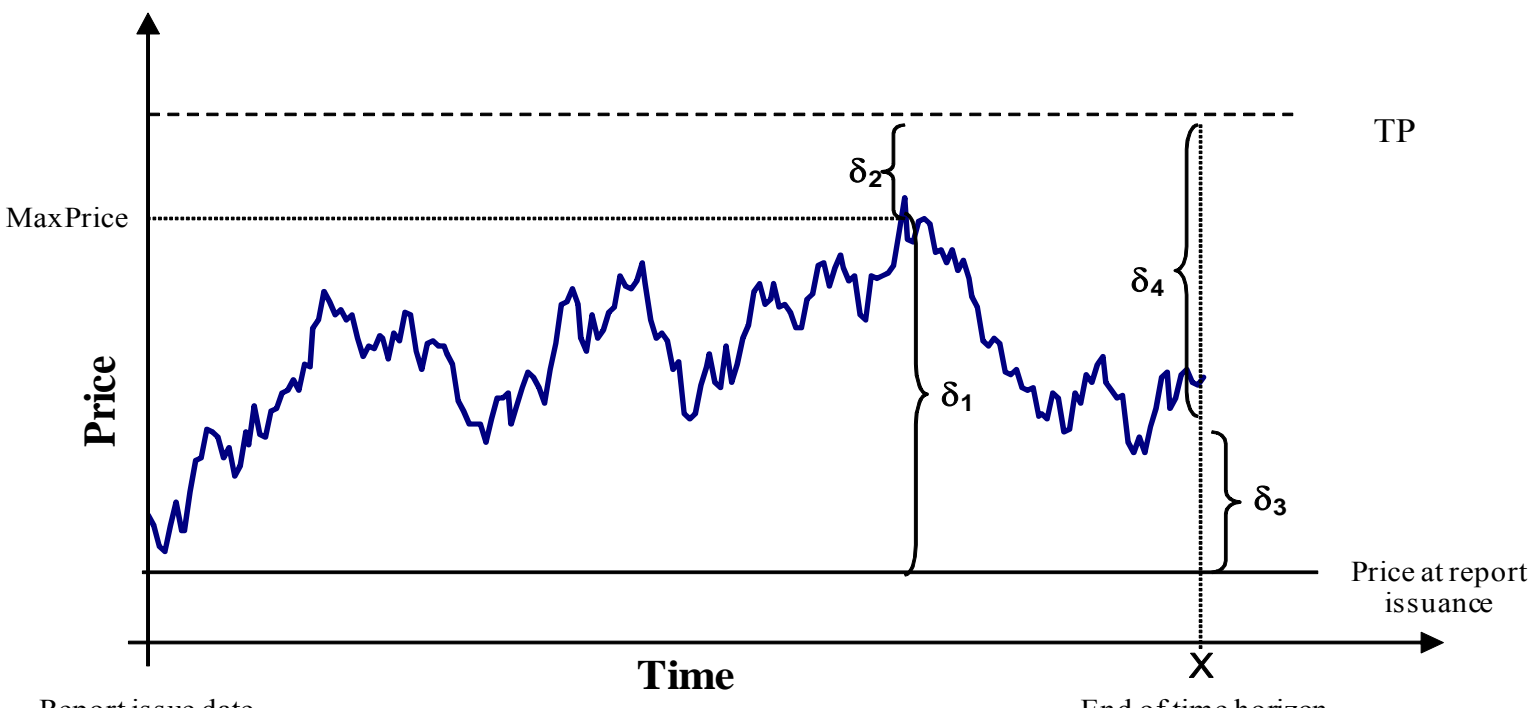

Report issue date

End of time horizon 
FIGURE 2

Variables' construction and sign interpretation

Variables are constructed as follows: if TP is greater than market price at t (top side of the graph), a positive sign for variables $\delta_{2} \delta_{4}$ means that TP has proved to be greater than the realized market price at the end of the time horizon. We name this event as "overshooting". A negative sign means that the realized market price has exceeded the issued TP: we define this recommendation to be "conservative". For the bottom part of the graph (when TP is lower than current market price at $t$ ), overshooting occurs when we obtain a positive sign i.e.when the issued TP is lower than the realized market price.

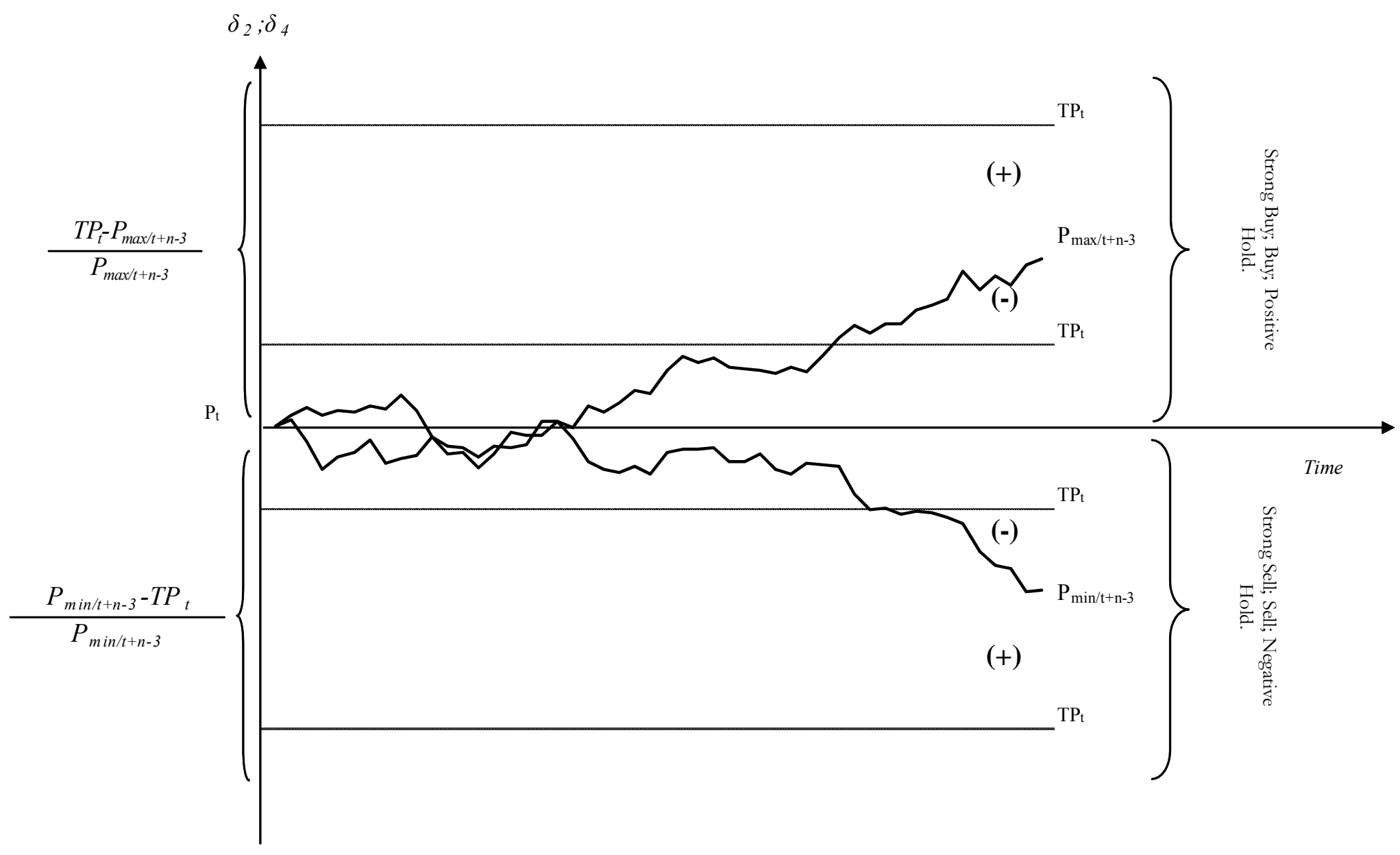




\section{Appendix A}

\section{Target Price accuracy - Yearly summary statistics}

This table shows YEARLY summary statistics for implicit returns, target price revisions and accuracy metrics. In Column 1 we report predicted implicit returns computed as the difference between target price and the market price at the issue date. In Column 2 we report the quantitative change in Target Price revisions measured as the percentage difference between a target price and its closest revision. Columns 3 and 4 report figures for the binary metric introduced by Bradshaw and Brown (2007), to allow comparis on with previous studies. TPmetANY indicates the percentage of reports for which the market price reaches the target price at any point during the TP prediction window. TPmetEND indicates the percentage of reports for which the market price has reached the TP at the end of th TP prediction window. Columns 5 and 6 report figures for the Ideal Strategy (IS) accuracy control metric and variable respectively. Columns 5 and 6 report figures for the Feasible Strategy (FS) accuracy control metric and variable respectively

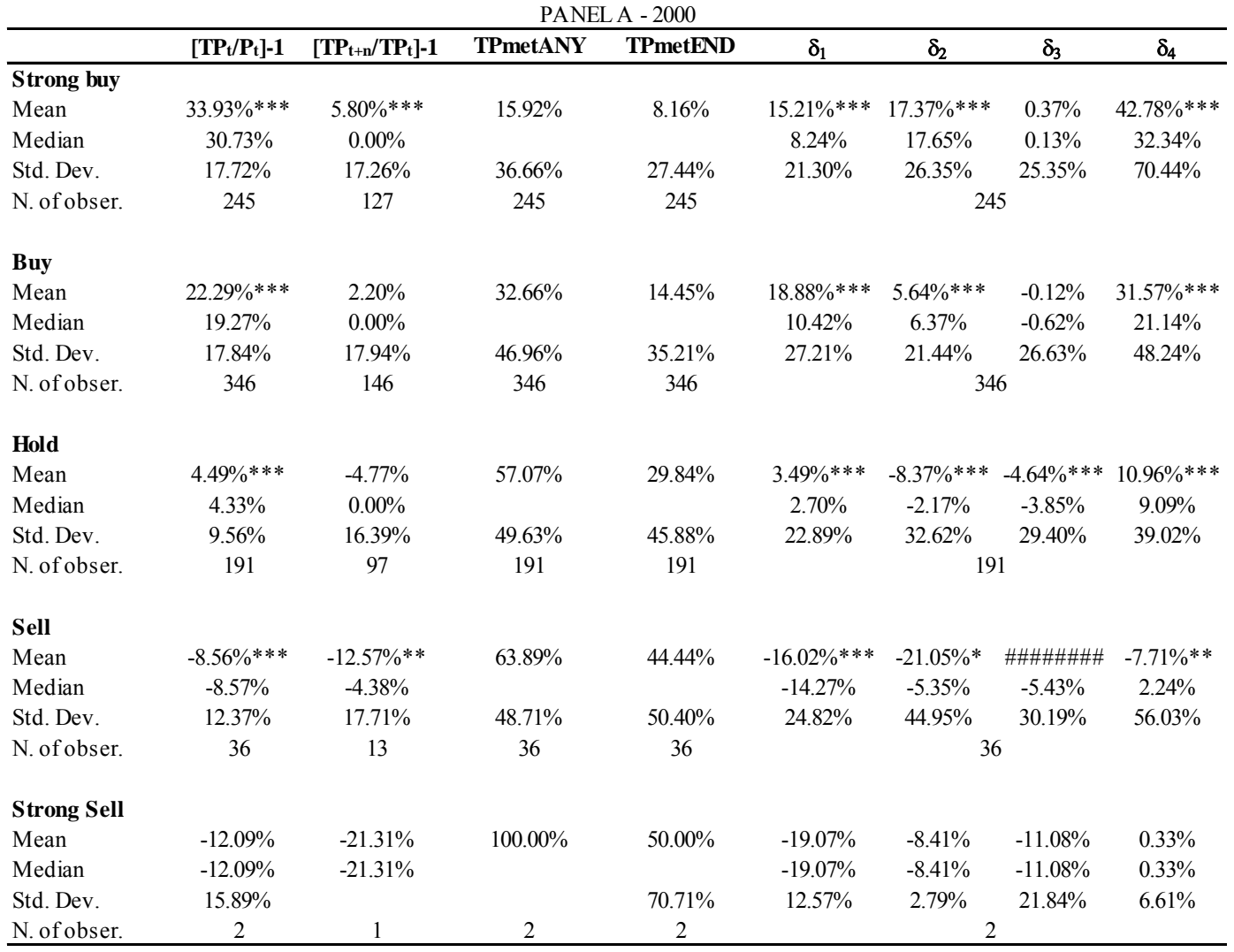


PANEL B - 2001

\begin{tabular}{|c|c|c|c|c|c|c|c|c|}
\hline & {$\left[T_{P} / P_{t}\right]-1$} & {$\left[T_{P_{t+n}} / T_{P}\right]-1$} & TPmetANY & TPmetEND & $\delta_{1}$ & $\delta_{2}$ & $\delta_{3}$ & $\delta_{4}$ \\
\hline \multicolumn{9}{|l|}{ Strong buy } \\
\hline Mean & $39.78 \% * * *$ & $3.01 \% * * *$ & $10.03 \%$ & $5.96 \%$ & $16.23 \% * * *$ & $22.62 \% * * *$ & $-3.14 \% * * *$ & $55.79 \% * * *$ \\
\hline Median & $33.44 \%$ & $0.00 \%$ & & & $8.74 \%$ & $21.43 \%$ & $-4.25 \%$ & $44.30 \%$ \\
\hline Std. Dev. & $23.62 \%$ & $27.86 \%$ & $30.09 \%$ & $23.70 \%$ & $22.31 \%$ & $22.21 \%$ & $27.00 \%$ & $57.64 \%$ \\
\hline N. of obser. & 319 & 239 & 319 & 319 & \multicolumn{4}{|c|}{319} \\
\hline \multicolumn{9}{|l|}{ Buy } \\
\hline Mean & $22.02 \% * * *$ & $-1.89 \%$ & $28.02 \%$ & $9.16 \%$ & $15.95 \% * * *$ & $7.01 \% * * *$ & $-5.28 \% * * *$ & $37.14 \% * * *$ \\
\hline Median & $19.58 \%$ & $0.00 \%$ & & & $9.11 \%$ & $7.40 \%$ & $-5.82 \%$ & $27.41 \%$ \\
\hline Std. Dev. & $13.52 \%$ & $27.57 \%$ & $44.95 \%$ & $28.87 \%$ & $20.94 \%$ & $16.72 \%$ & $24.48 \%$ & $40.63 \%$ \\
\hline N. of obser. & 546 & 378 & 546 & 546 & \multicolumn{4}{|c|}{546} \\
\hline \multicolumn{9}{|l|}{ Hold } \\
\hline Mean & $7.61 \% * * *$ & $-8.55 \%$ & $50.10 \%$ & $26.00 \%$ & $5.54 \% * * *$ & $-8.44 \% * * *$ & $-9.30 \% * * *$ & $21.31 \% * * *$ \\
\hline Median & $6.25 \%$ & $-7.96 \%$ & & & $3.05 \%$ & $-0.09 \%$ & $-9.86 \%$ & $15.59 \%$ \\
\hline Std. Dev. & $12.64 \%$ & $34.27 \%$ & $50.05 \%$ & $43.91 \%$ & $28.83 \%$ & $37.15 \%$ & $30.37 \%$ & $48.96 \%$ \\
\hline N. of obser. & 477 & 358 & 477 & 477 & \multicolumn{4}{|c|}{477} \\
\hline \multicolumn{9}{|l|}{ Sell } \\
\hline Mean & $-11.11 \% * * *$ & $-22.39 \% * * *$ & $58.87 \%$ & $39.72 \%$ & $-21.00 \% * * *$ & $-35.35 \% *$ & $-9.68 \% * * *$ & $-7.67 \%$ \\
\hline Median & $-10.31 \%$ & $-22.22 \%$ & & & $-17.56 \%$ & $-6.73 \%$ & $-7.34 \%$ & $7.16 \%$ \\
\hline Std. Dev. & $14.43 \%$ & $23.99 \%$ & $49.38 \%$ & $49.11 \%$ & $26.74 \%$ & $88.18 \%$ & $29.05 \%$ & $77.47 \%$ \\
\hline N. of obser. & 141 & 106 & 141 & 141 & \multicolumn{4}{|c|}{141} \\
\hline \multicolumn{9}{|l|}{ Strong Sell } \\
\hline Mean & $-20.65 \% * * *$ & $-11.98 \%$ & $41.18 \%$ & $17.65 \%$ & $-11.29 \% * * *$ & $5.39 \% * * *$ & $-7.51 \% * * *$ & $15.97 \% * * *$ \\
\hline Median & $-13.27 \%$ & $-13.08 \%$ & & & $-10.49 \%$ & $3.28 \%$ & $-6.12 \%$ & $17.27 \%$ \\
\hline Std. Dev. & $16.10 \%$ & $31.47 \%$ & $50.73 \%$ & $39.30 \%$ & $15.66 \%$ & $29.10 \%$ & $13.95 \%$ & $21.01 \%$ \\
\hline N. of obser. & 17 & 15 & 17 & 17 & \multicolumn{4}{|c|}{17} \\
\hline
\end{tabular}

PANEL B - 2002

\begin{tabular}{|c|c|c|c|c|c|c|c|c|}
\hline & {$\left[T_{P_{t}} / P_{t}\right]-1$} & {$\left[T_{P_{t+n}} / T_{P}\right]-1$} & TPmetANY & TPmetEND & $\delta_{1}$ & $\delta_{2}$ & $\delta_{3}$ & $\delta_{4}$ \\
\hline \multicolumn{9}{|l|}{ Strong buy } \\
\hline Mean & $40.14 \% * * *$ & $-3.51 \% * * *$ & $6.10 \%$ & $2.85 \%$ & $11.79 \% * * *$ & $26.50 \% * * *$ & $-2.99 \% * * *$ & $50.17 \% * * *$ \\
\hline Median & $36.27 \%$ & $0.00 \%$ & & & $8.38 \%$ & $24.60 \%$ & $-3.40 \%$ & $43.92 \%$ \\
\hline Std. Dev. & $20.61 \%$ & $20.09 \%$ & $23.98 \%$ & $16.66 \%$ & $12.92 \%$ & $20.61 \%$ & $18.31 \%$ & $41.97 \%$ \\
\hline N. of obser. & 246 & 196 & 246 & 246 & \multicolumn{4}{|c|}{246} \\
\hline \multicolumn{9}{|l|}{ Buy } \\
\hline Mean & $24.54 \% * * *$ & $-4.50 \% * * *$ & $13.33 \%$ & $4.44 \%$ & $10.34 \% * * *$ & $13.69 \% * * *$ & $-6.15 \% * * *$ & $38.10 \% * * *$ \\
\hline Median & $22.16 \%$ & $0.00 \%$ & & & $6.94 \%$ & $12.96 \%$ & $-5.55 \%$ & $31.09 \%$ \\
\hline Std. Dev. & $15.80 \%$ & $17.76 \%$ & $34.02 \%$ & $20.62 \%$ & $12.89 \%$ & $14.73 \%$ & $18.49 \%$ & $35.13 \%$ \\
\hline N. of obser. & 675 & 549 & 675 & 675 & \multicolumn{4}{|c|}{675} \\
\hline \multicolumn{9}{|l|}{ Hold } \\
\hline Mean & $10.10 \% * * *$ & $-10.37 \%$ & $42.22 \%$ & $25.04 \%$ & $4.50 \% * * *$ & $-1.63 \% * * *$ & $-7.63 \% * * *$ & $20.93 \% * * *$ \\
\hline Median & $9.24 \%$ & $-5.71 \%$ & & & $4.35 \%$ & $1.88 \%$ & $-7.57 \%$ & $16.95 \%$ \\
\hline Std. Dev. & $19.08 \%$ & $24.40 \%$ & $49.43 \%$ & $43.37 \%$ & $21.04 \%$ & $29.42 \%$ & $22.14 \%$ & $42.93 \%$ \\
\hline N. of obser. & 559 & 455 & 559 & 559 & \multicolumn{4}{|c|}{559} \\
\hline \multicolumn{9}{|l|}{ Sell } \\
\hline Mean & $-10.37 \% * * *$ & $-17.10 \% * * *$ & $60.45 \%$ & $39.55 \%$ & $-16.79 \% * * *$ & $-16.98 \% *$ & $-9.39 \% * * *$ & $4.49 \% *$ \\
\hline Median & $-9.36 \%$ & $-14.32 \%$ & & & $-14.67 \%$ & $-6.61 \%$ & $-10.28 \%$ & $7.41 \%$ \\
\hline Std. Dev. & $16.10 \%$ & $26.60 \%$ & $49.03 \%$ & $49.03 \%$ & $23.80 \%$ & $40.43 \%$ & $28.32 \%$ & $39.70 \%$ \\
\hline N. of obser. & 177 & 148 & 177 & 177 & \multicolumn{4}{|c|}{177} \\
\hline \multicolumn{9}{|l|}{ Strong Sell } \\
\hline Mean & $-57.03 \% * * *$ & $-21.97 \%$ & $50.00 \%$ & $50.00 \%$ & $-44.71 \% *$ & $-37.83 \% * * *$ & $-38.15 \% * * *$ & $-8.95 \%$ \\
\hline Median & $-57.77 \%$ & $-21.88 \%$ & & & $-43.27 \%$ & $-1.04 \%$ & $-39.85 \%$ & $-0.04 \%$ \\
\hline Std. Dev. & $9.08 \%$ & $38.71 \%$ & $57.74 \%$ & $57.74 \%$ & $37.67 \%$ & $127.63 \%$ & $39.58 \%$ & $84.08 \%$ \\
\hline N. of obser. & 4 & 4 & 4 & 4 & \multicolumn{4}{|c|}{4} \\
\hline
\end{tabular}


PANEL D - 2003

\begin{tabular}{|c|c|c|c|c|c|c|c|c|}
\hline & {$\left[\mathrm{TP}_{\mathrm{t}} / \mathbf{P}_{\mathrm{t}}\right]-1$} & {$\left[T_{P_{t+n}} / T_{t}\right]-1$} & TPmetANY & TPmetEND & $\delta_{1}$ & $\delta_{2}$ & $\delta_{3}$ & $\delta_{4}$ \\
\hline \multicolumn{9}{|l|}{ Strong buy } \\
\hline Mean & $37.42 \% * * *$ & $2.09 \% * * *$ & $14.66 \%$ & $9.05 \%$ & $16.70 \% * * *$ & $19.09 \% * * *$ & $10.82 \% * * *$ & $25.85 \% * * *$ \\
\hline Median & $33.28 \%$ & $0.00 \%$ & & & $12.71 \%$ & $17.33 \%$ & $8.83 \%$ & $21.04 \%$ \\
\hline Std. Dev. & $20.79 \%$ & $17.27 \%$ & $35.44 \%$ & $28.75 \%$ & $15.57 \%$ & $19.85 \%$ & $15.48 \%$ & $23.34 \%$ \\
\hline N. of obser. & 232 & 218 & 232 & 232 & \multicolumn{4}{|c|}{232} \\
\hline \multicolumn{9}{|l|}{ Buy } \\
\hline Mean & $21.82 \% * * *$ & $2.65 \% * * *$ & $27.14 \%$ & $18.38 \%$ & $14.50 \% * * *$ & $7.61 \% * * *$ & $9.47 \% * * *$ & $13.16 \% * * *$ \\
\hline Median & $19.17 \%$ & $0.00 \%$ & & & $10.48 \%$ & $7.57 \%$ & $6.53 \%$ & $11.49 \%$ \\
\hline Std. Dev. & $14.20 \%$ & $19.42 \%$ & $44.49 \%$ & $38.75 \%$ & $15.72 \%$ & $14.96 \%$ & $15.66 \%$ & $18.37 \%$ \\
\hline N. of obser. & 925 & 853 & 925 & 925 & \multicolumn{4}{|c|}{925} \\
\hline \multicolumn{9}{|l|}{ Hold } \\
\hline Mean & $6.35 \% * * *$ & $-2.26 \%$ & $52.39 \%$ & $35.28 \%$ & $10.04 \% * * *$ & $-1.88 \% * * *$ & $8.76 \% * * *$ & $6.02 \% * * *$ \\
\hline Median & $5.01 \%$ & $0.00 \%$ & & & $5.91 \%$ & $-0.77 \%$ & $6.02 \%$ & $5.41 \%$ \\
\hline Std. Dev. & $15.78 \%$ & $19.29 \%$ & $49.98 \%$ & $47.82 \%$ & $19.97 \%$ & $14.96 \%$ & $18.22 \%$ & $18.73 \%$ \\
\hline N. of obser. & 754 & 687 & 754 & 754 & \multicolumn{4}{|c|}{754} \\
\hline \multicolumn{9}{|l|}{ Sell } \\
\hline Mean & $-9.06 \% * * *$ & $-7.00 \% * * *$ & $42.93 \%$ & $21.46 \%$ & $-2.85 \% *$ & $2.20 \% *$ & $5.76 \% * * *$ & $12.70 \% * * *$ \\
\hline Median & $-8.62 \%$ & $0.00 \%$ & & & $-4.59 \%$ & $2.35 \%$ & $2.36 \%$ & $12.84 \%$ \\
\hline Std. Dev. & $14.80 \%$ & $27.56 \%$ & $49.62 \%$ & $41.16 \%$ & $19.12 \%$ & $14.42 \%$ & $18.60 \%$ & $16.87 \%$ \\
\hline N. of obser. & 205 & 194 & 205 & 205 & \multicolumn{4}{|c|}{205} \\
\hline \multicolumn{9}{|l|}{ Strong Sell } \\
\hline Mean & $-43.97 \% * * *$ & $-25.61 \% * * *$ & $0.00 \%$ & $0.00 \%$ & $-9.71 \% * * *$ & $37.77 \% * * *$ & $-1.36 \% * * *$ & $42.80 \% * * *$ \\
\hline Median & $-47.01 \%$ & $-4.81 \%$ & & & $-7.99 \%$ & $42.12 \%$ & $0.05 \%$ & $48.56 \%$ \\
\hline Std. Dev. & $15.27 \%$ & $33.09 \%$ & $0.00 \%$ & $0.00 \%$ & $6.11 \%$ & $17.49 \%$ & $6.92 \%$ & $17.59 \%$ \\
\hline N. of obser. & 9 & 8 & 9 & 9 & \multicolumn{4}{|c|}{9} \\
\hline
\end{tabular}

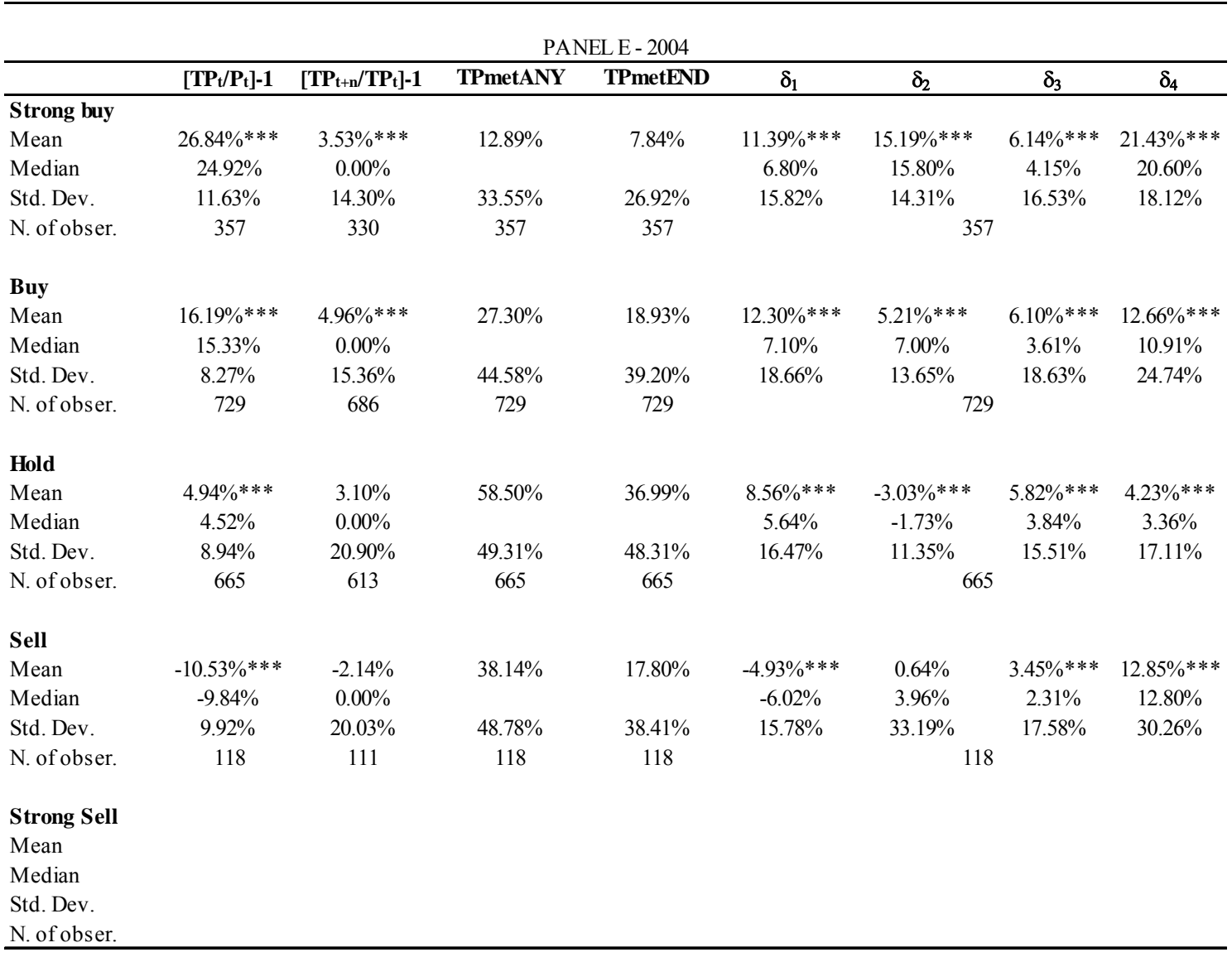


PANEL F - 2005

\begin{tabular}{|c|c|c|c|c|c|c|c|c|}
\hline & {$\left[T_{P} / P_{t}\right]-1$} & {$\left[T_{P_{t+n}} / T_{P}\right]-1$} & TPmetANY & TPmetEND & $\delta_{1}$ & $\delta_{2}$ & $\delta_{3}$ & $\delta_{4}$ \\
\hline \multicolumn{9}{|l|}{ Strong buy } \\
\hline Mean & $26.35 \% * * *$ & $8.71 \% * * *$ & $12.08 \%$ & $9.06 \%$ & $11.39 \% * * *$ & $15.37 \% * * *$ & $5.54 \% * * *$ & $22.32 \% * * *$ \\
\hline Median & $24.87 \%$ & $0.00 \%$ & & & $5.01 \%$ & $18.29 \%$ & $1.60 \%$ & $23.08 \%$ \\
\hline Std. Dev. & $15.10 \%$ & $26.91 \%$ & $32.64 \%$ & $28.75 \%$ & $18.91 \%$ & $17.96 \%$ & $18.43 \%$ & $20.72 \%$ \\
\hline N. of obser. & 298 & 278 & 298 & 298 & \multicolumn{4}{|c|}{298} \\
\hline \multicolumn{9}{|l|}{ Buy } \\
\hline Mean & $12.89 \% * * *$ & $6.17 \% * * *$ & $26.80 \%$ & $21.56 \%$ & $11.46 \% * * *$ & $3.23 \% * * *$ & $6.45 \% * * *$ & $8.50 \% * * *$ \\
\hline Median & $13.36 \%$ & $0.00 \%$ & & & $3.88 \%$ & $7.40 \%$ & $0.91 \%$ & $11.11 \%$ \\
\hline Std. Dev. & $5.07 \%$ & $19.89 \%$ & $44.32 \%$ & $41.15 \%$ & $19.89 \%$ & $13.13 \%$ & $19.29 \%$ & $14.74 \%$ \\
\hline N. of obser. & 667 & 642 & 668 & 668 & \multicolumn{4}{|c|}{668} \\
\hline \multicolumn{9}{|l|}{ Hold } \\
\hline Mean & $2.99 \% * * *$ & $4.52 \%$ & $46.77 \%$ & $27.86 \%$ & $7.23 \% * * *$ & $-2.33 \% * * *$ & $7.28 \% * * *$ & $4.93 \% * * *$ \\
\hline Median & $3.36 \%$ & $1.56 \%$ & & & $1.80 \%$ & $0.34 \%$ & $1.64 \%$ & $5.26 \%$ \\
\hline Std. Dev. & $7.36 \%$ & $17.86 \%$ & $49.93 \%$ & $44.86 \%$ & $17.83 \%$ & $11.40 \%$ & $19.12 \%$ & $14.36 \%$ \\
\hline N. of obser. & 682 & 666 & 682 & 682 & \multicolumn{4}{|c|}{682} \\
\hline \multicolumn{9}{|l|}{ Sell } \\
\hline Mean & $-8.86 \% * * *$ & $-1.66 \% * * *$ & $32.24 \%$ & $19.08 \%$ & $-4.41 \% * * *$ & $2.51 \% *$ & $6.28 \% * * *$ & $12.19 \% * * *$ \\
\hline Median & $-9.68 \%$ & $0.00 \%$ & & & $-3.31 \%$ & $4.93 \%$ & $1.87 \%$ & $11.42 \%$ \\
\hline Std. Dev. & $8.47 \%$ & $18.83 \%$ & $46.89 \%$ & $39.42 \%$ & $13.01 \%$ & $12.35 \%$ & $20.70 \%$ & $15.36 \%$ \\
\hline N. of obser. & 151 & 146 & 152 & 152 & \multicolumn{4}{|c|}{152} \\
\hline \multicolumn{9}{|l|}{ Strong Sell } \\
\hline Mean & $-31.47 \% * * *$ & $-3.26 \%$ & $5.77 \%$ & $1.92 \%$ & $-8.25 \% * * *$ & $24.62 \% * * *$ & $3.05 \% * * *$ & $32.27 \% * * *$ \\
\hline Median & $-27.01 \%$ & $0.00 \%$ & & & $-4.53 \%$ & $23.69 \%$ & $-0.55 \%$ & $32.38 \%$ \\
\hline Std. Dev. & $11.39 \%$ & $19.21 \%$ & $23.54 \%$ & $13.87 \%$ & $10.12 \%$ & $15.06 \%$ & $18.17 \%$ & $13.93 \%$ \\
\hline N. of obser. & 52 & 51 & 52 & 52 & \multicolumn{4}{|c|}{52} \\
\hline
\end{tabular}

PANEL G - 2006

\begin{tabular}{|c|c|c|c|c|c|c|c|c|}
\hline & {$\left[T_{P_{t}} / P_{t}\right]-1$} & {$\left[T_{P_{t+n}} / T_{P}\right]-1$} & TPmetANY & TPmetEND & $\delta_{1}$ & $\delta_{2}$ & $\delta_{3}$ & $\delta_{4}$ \\
\hline \multicolumn{9}{|l|}{ Strong buy } \\
\hline Mean & $65.43 \% * * *$ & $13.52 \% * * *$ & $12.06 \%$ & $10.05 \%$ & $12.74 \% * * *$ & $49.20 \% * * *$ & $4.67 \% * * *$ & $44.96 \% * * *$ \\
\hline Median & $26.00 \%$ & $0.00 \%$ & & & $6.00 \%$ & $19.00 \%$ & $2.00 \%$ & $22.00 \%$ \\
\hline Std. Dev. & $157.75 \%$ & $53.17 \%$ & $32.65 \%$ & $30.14 \%$ & $18.84 \%$ & $140.52 \%$ & $23.76 \%$ & $124.91 \%$ \\
\hline N. of obser. & 199 & 184 & 199 & 199 & \multicolumn{4}{|c|}{199} \\
\hline \multicolumn{9}{|l|}{ Buy } \\
\hline Mean & $14.26 \% * * *$ & $44.78 \% * * *$ & $22.68 \%$ & $14.88 \%$ & $10.89 \% * * *$ & $4.82 \% * * *$ & $5.61 \% * * *$ & $10.20 \% * * *$ \\
\hline Median & $14.00 \%$ & $0.00 \%$ & & & $5.00 \%$ & $8.00 \%$ & $2.00 \%$ & $11.00 \%$ \\
\hline Std. Dev. & $2.96 \%$ & $326.88 \%$ & $41.93 \%$ & $35.63 \%$ & $17.45 \%$ & $11.67 \%$ & $16.65 \%$ & $13.31 \%$ \\
\hline N. of obser. & 407 & 386 & 410 & 410 & \multicolumn{4}{|c|}{410} \\
\hline \multicolumn{9}{|l|}{ Hold } \\
\hline Mean & $3.17 \% * * *$ & $16.85 \%$ & $46.47 \%$ & $29.34 \%$ & $5.71 \% * * *$ & $-2.62 \% * * *$ & $3.73 \% * * *$ & $3.52 \% * * *$ \\
\hline Median & $5.00 \%$ & $0.00 \%$ & & & $2.00 \%$ & $0.00 \%$ & $1.00 \%$ & $4.00 \%$ \\
\hline Std. Dev. & $2.96 \%$ & $326.88 \%$ & $41.93 \%$ & $35.63 \%$ & $17.45 \%$ & $11.67 \%$ & $16.65 \%$ & $13.31 \%$ \\
\hline N. of obser. & 463 & 454 & 467 & 467 & \multicolumn{4}{|c|}{467} \\
\hline \multicolumn{9}{|l|}{ Sell } \\
\hline Mean & $-12.87 \% * * *$ & $6.64 \%$ & $8.70 \%$ & $0.00 \%$ & $-4.57 \% * * *$ & $8.30 \% *$ & $18.35 \% * * *$ & $24.17 \% * * *$ \\
\hline Median & $-12.00 \%$ & $0.00 \%$ & & & $-3.00 \%$ & $9.00 \%$ & $12.00 \%$ & $22.00 \%$ \\
\hline Std. Dev. & $2.47 \%$ & $33.27 \%$ & $28.81 \%$ & $0.00 \%$ & $4.85 \%$ & $6.24 \%$ & $21.84 \%$ & $12.30 \%$ \\
\hline N. of obser. & 23 & 20 & 23 & 23 & \multicolumn{4}{|c|}{23} \\
\hline \multicolumn{9}{|l|}{ Strong Sell } \\
\hline Mean & $-36.00 \% * * *$ & $187.68 \% * * *$ & $7.69 \%$ & $0.00 \%$ & $-8.92 \% * * *$ & $28.62 \% * * *$ & $8.77 \% * * *$ & $40.54 \% * * *$ \\
\hline Median & $-39.00 \%$ & & & & $-2.00 \%$ & $37.00 \%$ & $2.00 \%$ & $42.00 \%$ \\
\hline Std. Dev. & $12.57 \%$ & $620.88 \%$ & $27.74 \%$ & $0.00 \%$ & $13.24 \%$ & $16.11 \%$ & $19.47 \%$ & $10.40 \%$ \\
\hline N. of obser. & 13 & 12 & 13 & 13 & \multicolumn{4}{|c|}{13} \\
\hline
\end{tabular}




\section{Endnotes}

${ }^{\mathrm{i}}$ Information on revenues from equity research sales is obtained by investment banks and independent firms' annual reports.

${ }^{i i}$ See Stickel $(1990,1992,1995)$ Cooper et al. (2001) and Bernhardt et al. $(2004,2005)$.

iii We reject the observation that investors could perform accurate analysis of each research paper because more than 50,000 reports are published every year worldwide according to Thomson Financial and their average retail cost offered by sources like WSJ, FT or Yahoo Finance, among others, ranges at 30 USD, thus making a comprehensive analysis impossible for the vast majority of investors. As illustrated in the database section, Italy is an exceptional case since research is available freely through the Stock Exchange website which provides a motivation for this research.

iv The Code is known as TUF or Testo Unico della Finanza. Section IV refers to public information disclosure, or Comunicazioni al pubblico.

${ }^{v}$ Unfortunately we have no historical information to sort reports published immediatly from those delayed.

${ }^{v i}$ The JCF dataset figure is unfiltered therefore it must be compared with our full sample of 16,000 observations.

vii An interesting case is given by the removal and complete unavailability of Lehman Brothers Estimate from the Firs Call I/B/E/S Database in August 2009.

viii We thank an anonymous referee for suggesting this additional research question.

${ }^{\mathrm{ix}}$ By damaged we mean unreadable or empty. Mirror reports are defined as identical reports published twice under two different filename or classification.

${ }^{\mathrm{x}}$ Some examples include: mistakes in publications, corrections in data originated and released by the reported company.

${ }^{x i}$ See Womack (1996).

xii Throughout this paper we are interested in trying to understand the predictive ability of each research firm. We therefore analyze every recommendation as a stand alone investment indicator. We exclude, differently from other papers, investment strategies based on either static portfolio diversification or a fortiori dynamic portfolio allocation. Clearly, any consensus-driven or deep-diversified investment strategy reduces the non-systematic risk for any investor but risk reduction actions are out of the scope of this research. We believe this approach to be more consistent with small, uninformed investors' strategies which are more subject to sub-optimal diversification and to be driven in their allocation decisions by analyst recommendations. Furthermore, results in terms of analyst's individual performance are not affected by this assumption.

xiii We manually inspected all 9827 .pdf reports collecting the analyst's forecasting period for each target price. Almost all reports provide an explicit forecasting period and it is generally 12 months. For those reports which didn't explicitly disclose it, we cross-checked the company's disclosure notes to see whether they provided any indication. Lastly, we adopted the Association of Financial Analysts Guidelines which indicate that the standard forecasting horizon is 12 months unless differently stated.

xiv This last adjustment is made to take into account any possible information leakage around the new report date: as in Welch (2000) and Barucci et al. (2003), analysts tend to concentrate publishing reports around the same date, thus prices effects could be potentially cross-influenced by other research. This last evidence is also supported by the data in Table 2, Panel A.

${ }^{\mathrm{xv}}$ The case represents a positive implicit return target price forecast.

${ }^{x v i}$ In both directions: upwards and downwards according to the relevant recommendation.

${ }^{\text {xvii }}$ Furthermore, several times the maximum (minimum) price empirically calculated ex-post, is exactly the issuing date market price. This means that a particular share over the relevant time-horizon has shown a monotonically decreasing (increasing) market price.

xviii If the end of the time horizon is a research update we consider the update release date minus three days as explained in section 4.1.

xix This evidence can be interpreted as an indirect corroboration of previous studies on the effect on market prices of research publication.

${ }^{x x}$ We thank Christian Brownlees at the NYU Volatility Institute for suggesting this approach.

${ }^{x x i}$ See Falkenstein (1996) among others. 